\title{
Possíveis tratamentos farmacológicos em fase de estudos para pacientes sintomáticos de COVID-19:Uma revisão integrativa
}

\author{
Possible pharmacological treatment in study phase for COVID-19 symptomatic patients: An \\ integrative review \\ Posibles tratamientos farmacológicos en estudio para pacientes sintomáticos de COVID-19: Una \\ revisión integradora
}

Recebido: 28/04/2021 | Revisado: 06/05/2021 | Aceito: 15/05/2021 | Publicado: 03/06/2021

\author{
Danielle Guimarães Silva \\ ORCID: https://orcid.org/0000-0002-5132-3438 \\ Universidade São Judas Tadeu, Brasil \\ E-mail: dah.gs@hotmail.com \\ Renan Tripode Bartaquini \\ ORCID: https://orcid.org/0000-0002-8908-5148 \\ Universidade São Judas Tadeu, Brasil \\ E-mail: renan.bartaquini@gmail.com \\ Beatriz Moraes Pedrosa \\ ORCID: https://orcid.org/0000-0001-8898-3985 \\ Universidade São Judas Tadeu, Brasil \\ E-mail: moraesbeatriz2018@gmail.com \\ Carolina Heitmann Mares Azevedo Ribeiro \\ ORCID: https://orcid.org/0000-0002-9457-2733 \\ Universidade Federal do Pará, Brasil \\ E-mail: chribeiro@ufpa.br \\ Ana Cristina Lo Prete \\ ORCID: https://orcid.org/0000-0002-2874-5296 \\ Universidade São Judas Tadeu, Brasil \\ E-mail: analoprete@gmail.com
}

\begin{abstract}
Resumo
Objetivo: Realizar uma revisão integrativa sobre os possíveis tratamentos farmacológicos estudados atualmente como estratégias terapêuticas para pacientes COVID-19 positivos. Métodos: Foi realizada uma revisão integrativa de estudos da base de dados Medical Literature Analysis and Retrieval System, no sistema de busca PUBMED, na qual foram selecionados 58 artigos abordando 9 classes de fármacos. Resultados: A distribuição dos 58 artigos incluídos na revisão foi categorizada por fármaco abordado. Foram considerados tratamentos com melhoras significativas os que observaram redução de carga viral, redução do tempo de internação ou melhora clínica estatisticamente relevantes de acordo com os critérios de cada estudo. Conclusão: Com a urgência da produção rápida de resultados, foi observado que há uma grande dificuldade de produção de ensaios clínicos cego, duplo cego, fazendo com que a comunidade científica se restrinja principalmente a estudos retrospectivos e observacionais, que não são tão eficientes quanto os citados anteriormente. Com base na observação dos estudos, ainda não há um tratamento eficaz para a COVID-19, sendo crucial a aplicação de medidas preventivas, a fim de evitar o impacto da doença na população.
\end{abstract}

Palavras-chave: Possíveis Tratamentos; COVID-19; Pandemia; Novo Coronavírus; SARS-CoV-2.

\begin{abstract}
Objective: To perform an integrative review regarding the possible pharmacologic treatment currently being studied as therapeutics strategy for COVID-19 positive patients. Methods: An integrative review was performed using studies in the Medical Literatura Analysis and Retrieval System database, in the PUBMED search engine, in which were selected 58 articles regarding 9 pharmacological classes. Results: The distribution of the 58 articles included in this review was categorized by approached drug type. Were considered treatment with significant improvement the ones which presented viral load decrease, hospital time decrease or with statistically significant clinical improvement according to the criteria of each publication. Conclusion: Considering the urgency of the rapid production of results, a great difficulty of production of blind and double-blind studies was observed, limiting the scientific community to retrospective and observational studies, mostly, which are not as efficient as the mentioned before. Based on the studies observation, an efficient treatment to COVID-19 is not yet available, making the execution of preventive measures crucial, in order to avoid the impact of the disease in the population.
\end{abstract}


Keywords: Possible Treatments; COVID-19; Pandemic; New Coronavirus; SARS-CoV-2.

\begin{abstract}
Resumen
Objetivo: Realizar una revisión integradora de los posibles tratamientos farmacológicos que se están estudiando actualmente como estratégias terapéuticas para los pacientes COVID-19 positivos. Métodos: Se realizó una revisión integradora de estudios de la base de datos del Medical Literature Analysis and Retrieval System, mediante el sistema de búsqueda PUBMED, en la que se seleccionaron 58 artículos que abarcan 9 clases de fármacos. Resultados: La distribución de los 58 artículos incluidos en la revisión se categorizó por fármaco abordado. Se consideraron tratamientos con mejoría significativa aquellos que observaron una reducción de la carga viral, una reducción del tempo de hospitalización o mejoría clínica estadísticamente relevante según los criterios de cada estudio. Conclusión: Ante la urgencia de producir resultados rápidos, se observó que existe una gran dificultad en la realización de ensayos clínicos ciegos, doble ciego, haciendo con que la comunidad científica se restrinja principalmente a estudios retrospectivos y observacionales, los cuales no son tan eficientes como el anteriormente mencionado. Con base en la observación de los estudios, aún no existe un tratamiento efectivo para COVID-19, y la aplicación de medidas preventivas es crucial para evitar el impacto de la enfermedad en la población.
\end{abstract}

Palabras clave: Posibles tratamientos; COVID-19; Pandemia; Nuevo coronavirus; SARS-CoV-2.

\title{
1. Introdução
}

Em dezembro de 2019 uma epidemia de pneumonia viral aguda afetou a província de Hubei, na China. A doença, identificada como COVID-19 pela Organização Mundial de Saúde (OMS), teve como seu causador confirmado um vírus anteriormente desconhecido, nomeado SARS-CoV-2 (Severe Acute Respiratury Syndrome Coronavirus 2) pelo Comitê Internacional de Taxonomia de Vírus, devido à análise genômica apresentar proximidade filogenética com o anteriormente conhecido SARS-CoV, causador de uma epidemia viral no ano de 2002 (Lu et al., 2020; Yuen, Ye, Fung, Chan \& Jin, 2020).

Como consequência de sua alta transmissibilidade, com uma taxa de incidência de 83\% (Chan et al., 2020), e a possibilidade de transmissão assintomática (Bai et al., 2020), a COVID-19 foi considerada uma pandemia pela OMS em março de 2020, afetando mais de 150 países em setembro de 2020 (World Heath Organization [WHO], 2020a; WHO, 2020c).

Os coronavírus são vírus envelopados de RNA fita simples pertencentes à família Coronaviridae, tendo como estruturais as proteínas Spike (S), Envelope (E), de Membrana (M) e Nucleocapsídeo (N) (Fehr \& Perlman, 2015). Esse tipo de vírus infecta animais e o homem, podendo ser zoonóticos ou utilizarem animais como reservatórios, como a epidemia de SARS-CoV, originada em morcegos na China (W. Li et al., 2005).

O SARS-COV-2 se propaga por gotículas, secreções respiratórias e contato direto com superfícies infectadas. A infecção é instalada quando o vírus adentra as membranas mucosas, especialmente a nasal e da laringe, e então se instala nos pulmões, causando os sintomas iniciais mais comuns, que são febre e tosse (C. Huang et al., 2020). Ao se replicar, há a possibilidade de haver viremia, o que leva o vírus a órgãos alvo que expressam a enzima conversora de angiotensina 2 (ACE2), a qual o vírus utiliza como receptor para auxiliar sua entrada nas células, como os pulmões, coração, rins e trato gastrointestinal (Letko, Marzi \& Munster, 2020), uma vez que a glicoproteína S do vírion é capaz de se ligar à ACE2 (Tortorici \& Veesler, 2019).

Estima-se que o período entre a infecção e a manifestação dos sintomas seja em média 8 dias. No início dos sintomas pode haver leucopenia com linfopenia e, além disso, aproximadamente de 7 a 14 dias após a manifestação dos sintomas, há o aumento de fatores inflamatórios, como a IL-6, TNF-alfa e IL-10, o que corrobora com o agravo da doença (Wan et al., 2020). Vale ressaltar que esta reação inflamatória exacerbada é conhecida como tempestade de citocinas, e é uma das causas das lesões celulares graves que ocorrem nas células respiratórias (C. Huang et al., 2020).

Não há, até o momento, tratamento antiviral específico comprovado para a COVID-19, portanto, os tratamentos atuais focam principalmente em suporte respiratório e tratamento sintomático (Guo et al., 2020). Há, porém, estudos com fármacos que possuem potencial de combater a infecção por SARS-CoV-2, partindo de diversos mecanismos de ação.

Dois destes fármacos são a cloroquina e hidroxicloroquina, que apresentaram efeitos de inibição da infecção e propagação do SARS-CoV em células VERO E6 (Vincent et al., 2005), visto por alguns pesquisadores como um potencial 
fármaco de uso profilático e de tratamento da SARS-CoV-2 (N. Wang et al., 2020). Acredita-se que os mecanismos de ação da cloroquina e hidroxicloroquina no combate ao SARS-CoV-2 seja o bloqueio da entrada viral, pelo aumento do pH endossomal, impedindo a fusão à membrana celular, assim como por prejudicar a glicosilação terminal do ACE2, resultando na diminuição da afinidade destes receptores pelo SARS-CoV-2 (Vijayvargiya et al.,2020). Uma das características da cloroquina e hidroxicloroquina que pode ser levada em consideração no tratamento de COVID-19 é sua atividade imunomoduladora, por inibir ativação celular mediada por Receptores Toll-Like (TLRs) e produção de citocinas, além de inibir a ativação de células T via MHC de classe 2, reduzindo a produção de citocinas pró inflamatórias (Schrezenmeier \& Dörner, 2020).

Os antirretrovirais, como o lopinavir e ritonavir, também vêm sendo investigados para o tratamento da COVID-19 por atuarem na inibição da protease semelhante à 3-quimotripsina, a qual inibe a proliferação do vírus em sua célula hospedeira, por impedir a transcrição de RNA em DNA (Sanders, Monogue, Jodlowski \& Cutrell, 2020). O remdesivir também é um antiviral de largo espectro estudado, tendo tido sucesso no tratamento de pacientes com ebola, uma vez que inibe a RNA polimerase RNA-dependente, impedindo a replicação viral, o que o tornou alvo de estudos para o tratamento contra o novo coronavírus (Mulangu et al., 2019).

Outra estratégia de tratamento da COVID-19, ao invés de impedir a invasão do vírus nas células e replicação, tem foco na contenção da resposta inflamatória causada pelo vírus, reduzindo os danos causados por esta resposta e melhorando indiretamente a condição do paciente. Entre estes fármacos, podemos citar os corticosteroides, que são fármacos antiinflamatórios imunossupressores, os inibidores de citocinas inflamatórias, como o tocilizumabe, inibidor da IL-6, importante citocina relacionada com a resposta inflamatória da COVID-19, e os inibidores das enzimas sinalizadora de vias inflamatórias janus quinase (JAK), como o ruxolitinib (Esposito, Noviello \& Pagliano, 2020; Yeleswaram et al., 2020; Zhang et al., 2020).

Uma possível complicação da COVID-19, que causa grande piora de prognóstico são anormalidades de coagulação intravascular, que podem causar tromboses e CID (Coagulação Intravascular Disseminada). Como tratamento ou profilaxia desta alteração, são administrados anticoagulantes, como a Heparina (Asakura \& Ogawa, 2020).

Desse modo, com as condições atípicas e emergenciais causadas por esta pandemia, o objetivo do presente estudo foi realizar uma revisão integrativa sobre os possíveis tratamentos farmacológicos que estão sendo estudados como estratégias de tratamento para pacientes testados positivos para COVID-19.

\section{Metodologia}

Trata-se de uma revisão integrativa da literatura. A análise foi realizada por meio do cruzamento das palavras-chave disponíveis nos Descritores em Ciências da Saúde (DECS). Foram usados os descritores “Tratamento" e "COVID-19” na língua portuguesa e inglesa. $\mathrm{O}$ trabalho tem como alvo a seguinte questão: quais são os possíveis tratamentos farmacológicos para a COVID-19?

As buscas foram realizadas na base de dados Medical Literature Analysis and Retrieval System on-line (PUBMED), uma vez que esta base permite buscas simultâneas nas principais fontes nacionais e internacionais. Foram encontradas 3.183 publicações para a associação dos descritores no banco de dados mencionado.

A fase de análise dos artigos está relacionada com diferentes trabalhos selecionados de acordo com a questão da pesquisa, a fim de obter resultados para responder às mesmas, e assim conseguir alcançar os objetivos do estudo. Pelas categorias apresentadas, buscou-se responder o trabalho tomando como base os artigos incluídos que foram pertinentes à busca ativa.

Com base para os critérios de inclusão, foram selecionados os artigos com disponibilidade na íntegra e gratuitos, publicados em inglês, português e espanhol, no período de novembro de 2019 até agosto de 2020, e que continham referência aos descritores selecionados. 
Os filtros aplicados foram: estudo clínico, ensaio clínico, ensaio clínico fase I, ensaio clínico fase II, ensaio clínico fase III, ensaio clínico fase IV, protocolo de ensaio clínico, estudo comparativo, ensaio clínico controlado, artigo de revista científica, estudo observacional, estudo multicêntrico, ensaio clínico pragmático, ensaio clínico randomizado e estudo feitos em humanos.

Como critérios de exclusão, foram retirados do estudo, artigos de revisão bibliográfica, estudos que não abordam tratamento, que não apresentavam resultados, que se enquadram em categorias de modelo de carta, modelo de editorial, artigos in vitro e artigos in silico e, por fim, os relatos de caso, por não se tratarem de artigos de forte evidência científica.

Apesar de uso dos filtros para a seleção de artigos experimentais abertos nas línguas Português e Inglês, artigos não experimentais e em idiomas não selecionados foram apresentados pelo sistema de busca.

Desse modo, dos 3.182 artigos, foram excluídos 3.124. Desses, 1.335 eram artigos em categoria de revisão e 1.672 artigos que não abordam sobre tratamento, além de 35 artigos de estudos in vitro ou in silico, 11 artigos em idiomas não correspondentes às pesquisas e 94 relatos de caso. Após a leitura classificatória do resumo e do texto na íntegra, 58 artigos foram incluídos.

\section{Resultados}

A distribuição dos 58 artigos incluídos na revisão foi categorizada por fármaco abordado, dos quais: 14 artigos sobre hidroxicloroquina e cloroquina, 11 artigos sobre tocilizumabe, 10 artigos sobre lopinavir/ritonavir, 3 artigos sobre remdesivir, 7 artigos sobre interferons, 3 artigos sobre ruxolitinib, 1 artigo sobre heparina, 4 artigos sobre corticosteroides e 5 artigos sobre ribavarina. As principais informações dos artigos, como autor, tipo de estudo, período do estudo, tempo de tratamento, dose do fármaco, categoria do paciente estudado, se houve melhora clínica ou baixa de mortalidade estatisticamente significante, se houve grupo controle e o número de pacientes estudados, estão apresentadas a seguir nas tabelas de 1 a 9 , categorizadas de acordo com as classes terapêuticas descritas neste parágrafo.

Foram considerados tratamentos com melhoras significativas os que observaram redução de carga viral, redução do tempo de internação ou melhora clínica estatisticamente relevantes de acordo com os critérios de cada estudo. 
Research, Society and Development, v. 10, n. 6, e37910615579, 2021

(CC BY 4.0) | ISSN 2525-3409 | DOI: http://dx.doi.org/10.33448/rsd-v10i6.15579

Tabela 1: Artigos selecionados sobre hidroxicloroquina e cloroquina.

\begin{tabular}{|c|c|c|c|c|c|c|c|c|c|c|}
\hline Antigo & Autor & $\begin{array}{l}\text { Tipo de } \\
\text { Estudo }\end{array}$ & $\begin{array}{l}\text { Perlodo } \\
\text { do Estudo }\end{array}$ & $\begin{array}{l}\text { Tempo de } \\
\text { Tratamento }\end{array}$ & Dose & $\begin{array}{l}\text { Tipo de } \\
\text { Paciente }\end{array}$ & $\begin{array}{l}\text { Hourve melhora } \\
\text { clinica? }\end{array}$ & $\begin{array}{l}\text { Houve baika de } \\
\text { mortailidade? }\end{array}$ & $\begin{array}{c}\text { Grupo } \\
\text { Contrale }\end{array}$ & $\begin{array}{c}\text { Qual o } \\
n ?\end{array}$ \\
\hline 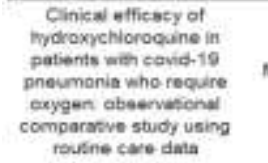 & $\underset{\text { ai. }}{\text { Mahdias, }}$ & $\begin{array}{l}\text { Estude } \\
\text { obsorvacion } \\
\text { al } \\
\text { enmparativo }\end{array}$ & $\begin{array}{l}12.31 \text { de } \\
\text { Março }\end{array}$ & 2 dias & 600 morisa & $\begin{array}{l}\text { Pacientes com } \\
\text { proumonia qae } \\
\text { requerem } \\
\text { oxigatrio, mas } \\
\text { nio vatamento } \\
\text { inteneivo }\end{array}$ & Nbo & NSO & $\begin{array}{l}\text { Sim, } 89 \\
\text { pacientes }\end{array}$ & 181 \\
\hline 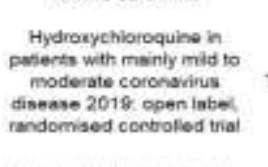 & Tang. W, et at, & 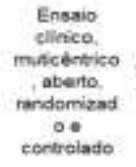 & $\begin{array}{l}11 \text { a } 29 \text { de } \\
\text { Fevereivo }\end{array}$ & $\begin{array}{l}\text { Dase inieial: } 3 \\
\text { dias } \\
\text { Manulençấs: } 2 \text {, } \\
\text { a J semanas. }\end{array}$ & $\begin{array}{l}\text { Dose incicial } \\
1200 \text { mgidia. } \\
\text { Manutençás } 800 \\
\text { mgida. }\end{array}$ & $\begin{array}{l}\text { Pacientes com } \\
\text { COVID-19 } \\
\text { brimda a } \\
\text { moderada }\end{array}$ & $\mathrm{sm}$ & NGlo informado & $\begin{array}{l}\sin , 75 \\
\text { posientes }\end{array}$ & 150 \\
\hline 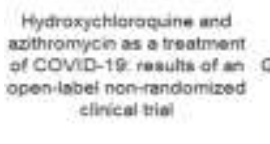 & Gaultet, $P$, of ai & $\begin{array}{c}\text { Eutudo } \\
\text { transversal }\end{array}$ & $\begin{array}{l}1 \text { and } 16 \text { de } \\
\text { Marso }\end{array}$ & $\begin{array}{l}10 \text { dias, } \\
\text { acompanthame } \\
\text { nto por } 14 \text { dias }\end{array}$ & $200 \mathrm{mg} 3$ xidia & $\begin{array}{l}\text { Pacientes: } \\
\text { assimomescos; } \\
\text { ou cam infecska } \\
\text { do trato } \\
\text { raspiratbrio } \\
\text { suoenor ou }\end{array}$ & $\mathrm{sm}$ & Nalo informato & $\begin{array}{c}\text { Sien, } 16 \\
\text { pacientios }\end{array}$ & 38 \\
\hline $\begin{array}{l}\text { Treating COVID-19 with } \\
\text { Chloroquins }\end{array}$ & Huang $M$ of al & $\begin{array}{l}\text { Ensais } \\
\text { clinico }\end{array}$ & $\begin{array}{l}27 \text { de } \\
\text { Janeive de } \\
\text { a } 15 \text { de } \\
\text { Fevereice }\end{array}$ & 10 dias & $500 \mathrm{mg} 2 \times 0$ din & $\begin{array}{l}\text { Pacientes } \\
\text { grevese } \\
\text { moderados }\end{array}$ & $\operatorname{sim}$ & Nalo informado & $\begin{array}{c}\operatorname{Sim}_{1} 12 \\
\text { pasiectos }\end{array}$ & 22 \\
\hline 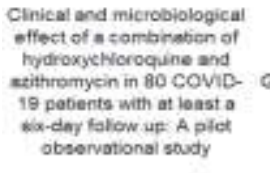 & Ginderte P et at & $\begin{array}{c}\text { Estudo } \\
\text { observacian } \\
\text { al }\end{array}$ & $\underset{\text { Abei }}{\text { Março an }}$ & $\begin{array}{l}10 \text { das. } \\
\text { Aztermicina } 5 \\
\text { dias }\end{array}$ & $\begin{array}{l}200 \mathrm{mgg} 3 \text { 3widia . } \\
500 \mathrm{mg} \\
\text { Astromicina D1 } \\
\text { seguido do 250 } \\
\text { mg }\end{array}$ & 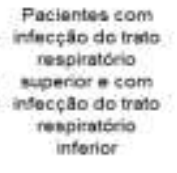 & $\sin$ & Nöo intoramado & Năo & 80 \\
\hline $\begin{array}{l}\text { Treatiment with } \\
\text { mydroxycklorequine, } \\
\text { aztiromyein, and } \\
\text { combinatsen in pasients } \\
\text { hospitaized with Covilo-19 }\end{array}$ & Arshod, 5. es as: & $\begin{array}{l}\text { Estudo } \\
\text { comparativo } \\
\text { retrospoctiv } \\
\text { o de eborte }\end{array}$ & $\begin{array}{l}10 \text { de } \\
\text { Marcos } 2 \\
\text { de Abrit }\end{array}$ & 5 dias & $\begin{array}{l}\text { Dia 1: } 400 \mathrm{mg} \\
\text { 2xidia. } \\
\text { Manutengso } 200 \\
\text { mg 2xidia }\end{array}$ & $\begin{array}{c}\text { Pacientes aem } \\
\text { doencos } \\
\text { cardiacas }\end{array}$ & Inconchasivo & $\operatorname{sim}$ & $\begin{array}{l}\text { Sim. ses } \\
\text { paciomos }\end{array}$ & 2541 \\
\hline 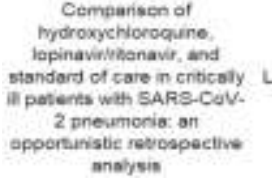 & $\begin{array}{c}\text { Locronier, } M \text { ot } \\
\text { al }\end{array}$ & $\begin{array}{l}\text { Estudo } \\
\text { camparativa a }\end{array}$ & $\begin{array}{l}4 \text { do Marco } \\
\text { a } 8 \text { de Abril }\end{array}$ & 5 dias & $200 \mathrm{mg} 2$ vidia & $\begin{array}{c}\text { Pacientes } \\
\text { graves } \\
\text { internadas em } \\
\text { UTI }\end{array}$ & NBSO & NAo intormado & $\begin{array}{c}\text { Sim, } 22 \\
\text { paciemes }\end{array}$ & 80 \\
\hline $\begin{array}{l}\text { Obuervational Study of } \\
\text { Hydroxyehioroquine in } \\
\text { Hospitaliced Fatiants wim } \\
\text { Conid. } 19\end{array}$ & Geieris S ot al. & $\begin{array}{l}\text { Estudo } \\
\text { obsecvesion } \\
\text { at }\end{array}$ & $\begin{array}{c}07 \text { de } \\
\text { Marşo a } 8 \\
\text { de Abril }\end{array}$ & & & $\begin{array}{l}\text { Pacientes nío } \\
\text { ensibados }\end{array}$ & Näo & NSo & $\begin{array}{l}\text { Sim, S65 } \\
\text { pacientes }\end{array}$ & 1376 \\
\hline $\begin{array}{l}\text { Early troatmont of COViD. } \\
19 \text { patients with } \\
\text { Hydroxychioroquine and } \\
\text { azithromyein. A } \\
\text { ratrespective analyais of } \\
\text { 1061 cases in Marseite. } \\
\text { France }\end{array}$ & Mition, M. et at. & $\begin{array}{c}\text { Eosido } \\
\text { etrospectey } \\
\text { o }\end{array}$ & $\begin{array}{l}3031 \text { do } \\
\text { Maç̧o }\end{array}$ & 10 das & $\begin{array}{l}200 \text { mgidis por } \\
10 \text { dias }\end{array}$ & $\begin{array}{l}\text { Pacientes } \\
\text { tratsdos com } \\
\text { Hidrovkioroquina } \\
\text { ne periado } \\
\text { estudado }\end{array}$ & $\operatorname{sim}$ & Nâo informado & Nåo & 1061 \\
\hline 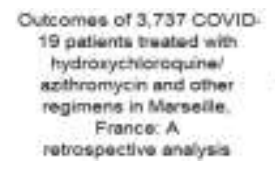 & Lager. J. et ail: & $\begin{array}{c}\text { Estudo } \\
\text { rovespectiv } \\
0\end{array}$ & $\begin{array}{c}3 \text { de Março } \\
-27 \text { do } \\
\text { Abnil }\end{array}$ & 10 dian & 200 mg 3xida & $\begin{array}{l}\text { Patientes } \\
\text { adultes } \\
\text { contirmados por } \\
\text { PCR no periodo }\end{array}$ & $\operatorname{sim}$ & Sim & $\begin{array}{l}\text { Sim. } 618 \\
\text { pacenten }\end{array}$ & 3737 \\
\hline 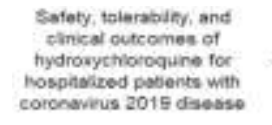 & Satsin, M, et ai & $\begin{array}{l}\text { Eatudo } \\
\text { observision } \\
\text { al }\end{array}$ & $\begin{array}{l}5025 \text { de } \\
\text { Merso }\end{array}$ & 5 diss & $\begin{array}{l}600 \text { mo } 2 x \text { itia } \\
\text { pos } 1 \text { dia, apds } \\
400 \text { mo/dia }\end{array}$ & $\begin{array}{l}\text { Psciectes } \\
\text { tratsdos com } \\
\text { Midrovicloroquina } \\
\text { o perfodo } \\
\text { estudado. }\end{array}$ & Inconclusivo & Intoncluasivo & NBbo & 141 \\
\hline 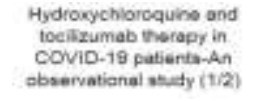 & ip, A. et al. & $\begin{array}{l}\text { Estudo } \\
\text { observection } \\
\text { at }\end{array}$ & $\begin{array}{l}1 \text { de Marce } \\
\text { a } 22 \text { de } \\
\text { Abril }\end{array}$ & 5 dias & $\begin{array}{l}800 \mathrm{mg} \text { da } 1 . \\
400 \mathrm{mg} \text { nos } \\
\text { segurtes }\end{array}$ & $\begin{array}{l}\text { Pacientes } \\
\text { pesithros a } \\
\text { imiarnadios. }\end{array}$ & Năo & Năo & $\begin{array}{l}\text { Sim, } 698 \\
\text { pacientas }\end{array}$ & 2512 \\
\hline 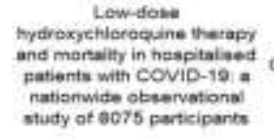 & Ceneau L ot $=$ & $\begin{array}{c}\text { Eatusb } \\
\text { obsernacion } \\
\text { al }\end{array}$ & $\begin{array}{c}14 \text { de } \\
\text { Março a } 24 \\
\text { de Maip }\end{array}$ & 5 dims & $\begin{array}{c}2400 \mathrm{mg} \text { a } 0606 \\
\text { mg idose total) }\end{array}$ & $\begin{array}{l}\text { Pacierries } \\
\text { maiores de } \\
\text { idade internastea }\end{array}$ & Näo informado & sim & $\begin{array}{l}\text { Sim } 3539 \\
\text { gacientas }\end{array}$ & as 10 \\
\hline 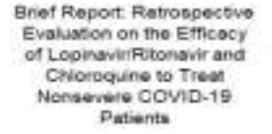 & Gao, G. et al & $\begin{array}{c}\text { Estudo } \\
\text { retrospectiv } \\
\text { e }\end{array}$ & $\begin{array}{l}20 \text { de } \\
\text { Janero a } \\
26 \text { de } \\
\text { Marçe }\end{array}$ & 7 dias & 500 mg 2nida & $\begin{array}{l}\text { Pacientes nso } \\
\text { severos empe } 18 \\
\text { - } 65 \text { enos }\end{array}$ & NSo & Nas infoemads & $\begin{array}{c}\text { Sim, } 68 \\
\text { pacientes }\end{array}$ & 129 \\
\hline
\end{tabular}

Fonte: Autores. 
Research, Society and Development, v. 10, n. 6, e37910615579, 2021

(CC BY 4.0) | ISSN 2525-3409 | DOI: http://dx.doi.org/10.33448/rsd-v10i6.15579

Tabela 2: Artigos selecionados sobre tocilizumabe.

\begin{tabular}{|c|c|c|c|c|c|c|c|c|c|c|}
\hline Artigo & Autof & $\begin{array}{l}\text { Tipo de } \\
\text { Estudo }\end{array}$ & $\begin{array}{l}\text { Periodo } \\
\text { do Estudo }\end{array}$ & $\begin{array}{l}\text { Tempo de } \\
\text { Tratamento }\end{array}$ & Dose & Tipo de Paciente & $\begin{array}{l}\text { Reuve } \\
\text { meihora } \\
\text { clinica? }\end{array}$ & $\begin{array}{l}\text { Houve baixa } \\
\text { de } \\
\text { mortalidade? } c\end{array}$ & $\begin{array}{l}\text { Orupo } \\
\text { Controle }\end{array}$ & Qual o $\mathrm{m}$ ? \\
\hline $\begin{array}{l}\text { Tocilaumab tratmemt in COVID-18: } \\
\text { A sing/e conter expenence }\end{array}$ & Lue, $P$, et al. & $\begin{array}{l}\text { Evido } \\
\text { atservacional } \\
\text { retospectivo }\end{array}$ & $\begin{array}{l}27 \text { de } \\
\text { danere a } 5 \\
\text { de Março }\end{array}$ & 1 dia & Variadas & $\begin{array}{l}\text { Paciemios graves } \\
\text { ou criticos }\end{array}$ & $\sin$ & Nล้อ & NASO & 15 \\
\hline $\begin{array}{l}\text { Off-abel use of tocilitumab for the } \\
\text { tremenent of SARS-Cov-2 } \\
\text { phetumania in Mian, haly }\end{array}$ & Morena $V$, ef at. & $\begin{array}{l}\text { Evisido } \\
\text { prospective } \\
\text { aberto }\end{array}$ & $\begin{array}{l}10 \text { a } 23 \text { de } \\
\text { Marco }\end{array}$ & 1 da & $\begin{array}{l}400 \mathrm{mg} \text { iv. segunda } \\
\text { dose ou } 8 \text { mgkg em } \\
\text { peciemes }>60 \mathrm{~kg}\end{array}$ & 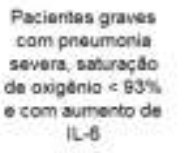 & $\operatorname{Sim}$ & Nabo informado & Nolo & 51 \\
\hline 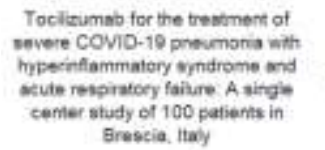 & Toniat, $P$ - ot al. & $\begin{array}{l}\text { Eatudo } \\
\text { retrospectivo }\end{array}$ & $\begin{array}{l}9.20 \text { de } \\
\text { Marşo }\end{array}$ & 1 a 2 das & 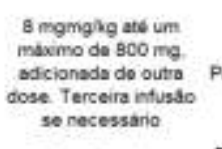 & Pacientes severos & $\mathrm{sm}$ & NSo intormado & NEO & 100 \\
\hline $\begin{array}{l}\text { Effective trosimert of severe } \\
\text { covid-18 patents wath locititumab }\end{array}$ & $x_{v,} x$ at al. & $\begin{array}{l}\text { Estudo } \\
\text { retrospectivo }\end{array}$ & $\begin{array}{l}\text { 5: } 14 \text { de } \\
\text { Fevereiro }\end{array}$ & 1 dia & $\begin{array}{l}\text { As s orokg ate um } \\
\text { masime de } 800 \text { mg, se } \\
\text { febre ors administrads } \\
\text { segunda dose }\end{array}$ & $\begin{array}{l}\text { Pasientes graves } \\
\text { ou enticos, com } \\
\text { saniraço do } \\
\text { oxigenio < } 93 \% \\
\text { em ar ambierto }\end{array}$ & $\sin$ & NBo informado & NEO & 21 \\
\hline 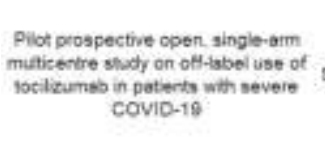 & Sciascia s, at al & $\begin{array}{l}\text { Estudo } \\
\text { prospectivo } \\
\text { mberto } \\
\text { maticenos }\end{array}$ & $\begin{array}{l}\text { Naso } \\
\text { informado }\end{array}$ & 2 dias & $\begin{array}{l}\text { 8 mokg ivifuma ou } \\
\text { duas doses) } 924 \text { mg or } \\
\text { s. (possivel segunda } \\
\text { dose de } 182 \mathrm{mg} \text { ) }\end{array}$ & 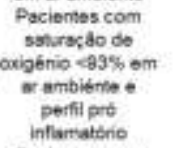 & $\mathrm{sm}$ & Naso informado: & NBO & 63 \\
\hline 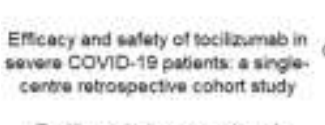 & $\begin{array}{l}\text { Campochiaro, C. } \\
\text { et ai. }\end{array}$ & $\begin{array}{l}\text { Eatude } \\
\text { retrospectivo } \\
\text { de coorto }\end{array}$ & $\begin{array}{l}\text { Noso } \\
\text { informade }\end{array}$ & $\begin{array}{l}2 \text { diss cass } \\
\text { piors }\end{array}$ & $400 \mathrm{mg} \mathrm{ix}$ & 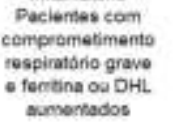 & NSo & Nsa & $\begin{array}{l}\text { Sim } 39 \\
\text { paciertites }\end{array}$ & 65 \\
\hline $\begin{array}{l}\text { Tocilizumab tharspy reduced } \\
\text { intonsive care unt admissions } \\
\text { andior mortaity in COViD-19 } \\
\text { patents }\end{array}$ & $\begin{array}{c}\text { Kleptenstorn. } T \text {. } \\
\text { et at. }\end{array}$ & $\underset{\text { Estudo }}{\text { retrospectivo }}$ & $\begin{array}{l}1 \text { de Marce } \\
\text { a } 13 \text { de } \\
\text { Abril }\end{array}$ & 1 ou 2 dias. & Năo infermado & $\begin{array}{l}\text { Paciemios com } \\
\text { colvi-19 severa }\end{array}$ & $\operatorname{sim}$ & $\operatorname{sim}$ & $\sin _{\text {pocientes }} 25$ & 45 \\
\hline 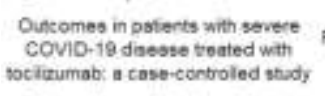 & Rajes-Mate, $Q$ at & $\begin{array}{l}\text { Estude } \\
\text { retrospectivo }\end{array}$ & $\begin{array}{l}\text { 8 de Março } \\
\text { - } 25 \text { de } \\
\text { Abnil }\end{array}$ & M5o informado & Náo informado & $\begin{array}{l}\text { Pacientes com } \\
\text { Covid-19 nevere } \\
\text { a critic }\end{array}$ & Năo & $\begin{array}{l}\text { Sim, quando } \\
\text { excluidos } \\
\text { pacientes } \\
\text { incibedos. }\end{array}$ & $\begin{array}{l}\text { Sim. } 95 \\
\text { pecientes }\end{array}$ & 183 \\
\hline 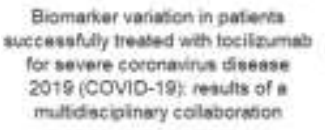 & $\begin{array}{c}\text { Conrozer, } T \text {. at } \\
\text { al. }\end{array}$ & $\begin{array}{l}\text { Estudo } \\
\text { retrospectivo }\end{array}$ & $\begin{array}{l}\text { I de Abril a } \\
11 \text { de Mais }\end{array}$ & 2 das & $\begin{array}{l}2 \text { doses. } 8 \mathrm{mglig} \text { ath } \\
\text { um maximo de } 900 \mathrm{mg}\end{array}$ & $\begin{array}{l}\text { Pecientes com } \\
\text { Covid-19 severa }\end{array}$ & $\operatorname{Sin}$ & Nbs inlormado & NE⿱⺈ & 40 \\
\hline $\begin{array}{l}\text { Hydroxyctioroquine and tocilizumab } \\
\text { therapy in covino-19 patiems-An. } \\
\text { obsarvatienal study (2:2) }\end{array}$ & Ip, A, et al & $\begin{array}{l}\text { Estudo } \\
\text { observacional }\end{array}$ & $\begin{array}{l}1 \text { de Março } \\
\text { a } 22 \text { de } \\
\text { Abril }\end{array}$ & $1 \mathrm{da}$ & $400 \mathrm{mg}$ & $\begin{array}{l}\text { Paciernes } \\
\text { inernados am } \\
\text { terapia intenaiva }\end{array}$ & $\operatorname{Sim}$ & Sm & $\begin{array}{l}\text { Sim } 413 \\
\text { pociontes }\end{array}$ & 611 \\
\hline $\begin{array}{l}\text { Toclesumab and stbroid treatinert in } \\
\text { palents wh coviD-19 pneumenia }\end{array}$ & Ninulska, M. ot at. & $\begin{array}{l}\text { Entudo } \\
\text { observatione }\end{array}$ & $\begin{array}{l}\text { Nato } \\
\text { informade }\end{array}$ & 1 da & $\begin{array}{l}\text { B mgkg ix, eu } 162 \mathrm{mg} \\
\text { s.c. }\end{array}$ & $\begin{array}{l}\text { Pacientes que nlo } \\
\text { gstavam em UTI } \\
\text { som saturasha de } \\
\text { oxigetrio } 593 \%\end{array}$ & $\sin$ & $\operatorname{sim}$ & $\begin{array}{c}\operatorname{Sim} 60 \\
\text { pesientes }\end{array}$ & 215 \\
\hline
\end{tabular}

Fonte: Autores. 
Research, Society and Development, v. 10, n. 6, e37910615579, 2021

(CC BY 4.0) | ISSN 2525-3409 | DOI: http://dx.doi.org/10.33448/rsd-v10i6.15579

Tabela 3: Artigos selecionados sobre lopinavir/ritonavir.

\begin{tabular}{|c|c|c|c|c|c|c|c|c|c|c|}
\hline Artigo & Autor & Tho de Estuiso & $\begin{array}{l}\text { Periodo do } \\
\text { Estudo }\end{array}$ & $\begin{array}{l}\text { Trmpo de } \\
\text { Tratamento }\end{array}$ & Dose & Thpo de Pacients & $\begin{array}{l}\text { Heuve meithora } \\
\text { clinice? }\end{array}$ & $\begin{array}{l}\text { Houve baixs } \\
\text { de } \\
\text { mortalidade? }\end{array}$ & $\begin{array}{l}\text { Grupo } \\
\text { Controie }\end{array}$ & Oual on? \\
\hline $\begin{array}{l}\text { A Trial of Lopinavir-Potonavi } \\
\text { in Adien Hocaplaked Wath } \\
\text { Sevore Covid-12 }\end{array}$ & $\mathrm{Cso} \mathrm{B}_{\mathrm{i}} \mathrm{et} \mathrm{at}$ & $\begin{array}{l}\text { Estuso } \\
\text { andomrada } \\
\text { copen-label }\end{array}$ & $\begin{array}{l}18 \text { de janeiro de } \\
2020 \text { \& } 3 \text { de } \\
\text { fovoreiro de } 2020\end{array}$ & 14 diass & $\begin{array}{l}400 \text { mine zochng } \\
\text { zedad }\end{array}$ & $\begin{array}{l}\text { Paocentes con } \\
\text { sabractio de uejgerio } \\
94 \$ \text { ou menos na ar } \\
\text { ambiente }\end{array}$ & Nalo & Ma & $\begin{array}{c}\text { sim, on } \\
\text { pacientes }\end{array}$ & 109 \\
\hline 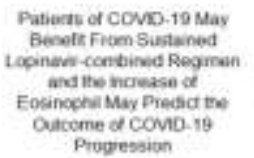 & Fare $L$ at $\alpha$ & $\begin{array}{l}\text { Estudo } \\
\text { merospecivo }\end{array}$ & $\begin{array}{l}22 \text { de janeiro de } \\
2020 \text { a } 11 \text { de } \\
\text { fevwireim de } 2000\end{array}$ & 5 das & 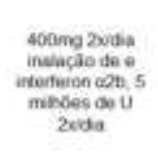 & $\begin{array}{l}\text { Pacietes intomadon } \\
\text { con CoMD-19 }\end{array}$ & $\mathrm{Bm}$ & Nos ifformado & Mas. & to \\
\hline 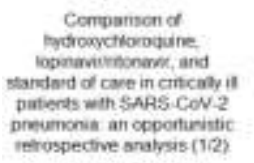 & Mane. L ef al & $\begin{array}{l}\text { Estudo } \\
\text { comosatuo }\end{array}$ & $\begin{array}{c}400 \text { marco de } \\
2000 \text { a } 6 \text { de atmil } \\
\text { de } 2020\end{array}$ & 20 din & 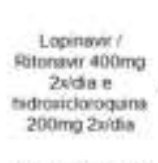 & $\begin{array}{c}\text { Pacontes insenaros } \\
\text { em Un com Covio. } 19 \\
\text { grave }\end{array}$ & Maso & Nos irformado & $\begin{array}{c}\operatorname{sim} .22 \\
\text { paroentes }\end{array}$ & 80 \\
\hline 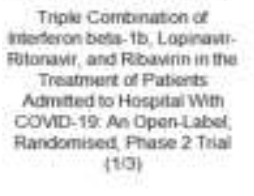 & $\operatorname{man} F$ et al & $\begin{array}{l}\text { Ethodo de tase } 1 \text {. } \\
\text { opon label } \\
\text { indomzzado }\end{array}$ & $\begin{array}{l}10 \text { de fevereiro de } \\
2020 \text { a } 20 \text { de } \\
\text { maco de } 2020\end{array}$ & 14 dios: & 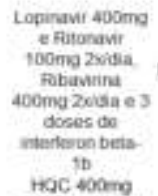 & $\begin{array}{l}\text { NEWS de peso menos } 1 \text {; } \\
\text { monog de } 14 \text { das de } \\
\text { sirtomas }\end{array}$ & $\sin$ & Nao irfomado & $\begin{array}{l}\text { Sim } 41 \\
\text { pacoentes }\end{array}$ & B6 \\
\hline 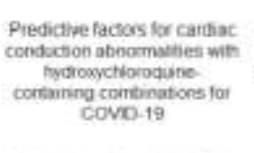 & Serga $P$ e et $a$. & $\begin{array}{l}\text { Estudo de coorte } \\
\text { prospectivo } \\
\text { locghidirat }\end{array}$ & $\begin{array}{l}10 \text { de marco de } \\
2020 \text { a } 17 \text { de atbet } \\
\text { de } 2020\end{array}$ & 10 diss & 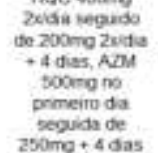 & $\begin{array}{l}\text { Paciertees com covo. } \\
\text { t9 e problemss } \\
\text { caldacos }\end{array}$ & $\mathrm{sm}$ & Naso irtomado & Noo: & 106 \\
\hline 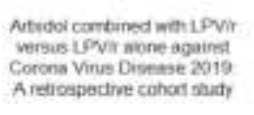 & Lisi, $0 \in \mathbb{a l}$ & $\begin{array}{l}\text { Exudo as cooste } \\
\text { Mtruppectivo }\end{array}$ & $\begin{array}{l}17 \text { de paneirs de } \\
2020 \text { a } 13 \text { de } \\
\text { tenereio de } 20600\end{array}$ & 21 des & 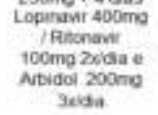 & 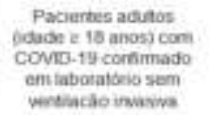 & $8 m$ & Mos intormadn & $\begin{array}{l}\text { Sam, 23 } \\
\text { pacomtes }\end{array}$ & 50 \\
\hline 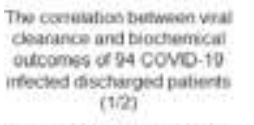 & $\operatorname{Jing} Y, \operatorname{st} \alpha$ & 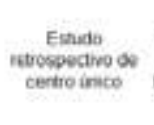 & $\begin{array}{l}11 \text { do janewo do } \\
2020 \text { a } 4 \$ 0 \\
\text { hevereiro de } 2020\end{array}$ & 16 Gas & No infomado & $\begin{array}{l}\text { Pacoetes com covid. } \\
19 \text { gN iecuberam ata } \\
\text { hosplatar }\end{array}$ & Sim & NSo infermade & Nào & 94 \\
\hline 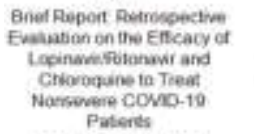 & Gao 6 otal & $\begin{array}{l}\text { Einado } \\
\text { etrosetcivo }\end{array}$ & $\begin{array}{l}\text { Tode janerco di } \\
2020 \text { a } 26 \text { de } \\
\text { marla de } 2020\end{array}$ & 7 das & 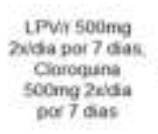 & $\begin{array}{l}\text { Pacientes PCR } \\
\text { poestivos, artre } 18 \text { es } \\
\text { ancos, năo severos }\end{array}$ & Mao & Wha infmmades & $\begin{array}{l}\text { Sim, } 59 \\
\text { pacientes: }\end{array}$ & 120 \\
\hline 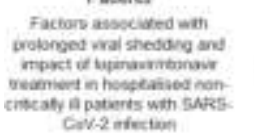 & Dan, $Y$ of al & $\begin{array}{l}\text { Eitudo } \\
\text { utrospedivo }\end{array}$ & $\begin{array}{l}31 \text { ss janero os } \\
20200900 \\
\text { marşo de } 2020\end{array}$ & 10 das. & $\begin{array}{c}400 m g=100 m y \\
2 x i t a\end{array}$ & $\begin{array}{l}\text { Pacietes infectados } \\
\text { com SARS -CON-2 hves } \\
\text { - grawes }\end{array}$ & $5 \mathrm{~m}$ & Măo informado & $\begin{array}{c}\operatorname{Sim}, 12 \\
\text { paccesales }\end{array}$ & 120 \\
\hline
\end{tabular}

Fonte: Autores.

Tabela 4: Artigos selecionados sobre remdesivir.

\begin{tabular}{|c|c|c|c|c|c|c|c|c|c|c|}
\hline \multicolumn{11}{|c|}{ Remdesivir } \\
\hline Artigo & Autor & $\begin{array}{l}\text { Tipo de } \\
\text { Estudo }\end{array}$ & $\begin{array}{l}\text { Periodo do } \\
\text { Estudo }\end{array}$ & $\begin{array}{l}\text { Tempo de } \\
\text { Tratamento }\end{array}$ & Dose & Tipo de Paciente & $\begin{array}{l}\text { Houve meihora } \\
\text { clinica? }\end{array}$ & $\begin{array}{l}\text { Houve baixa de } \\
\text { mortalidade? }\end{array}$ & $\begin{array}{c}\text { Grupo } \\
\text { Controle }\end{array}$ & Qual o N? \\
\hline 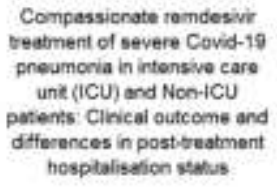 & Spinelo, A. et al. & $\begin{array}{l}\text { Estuda } \\
\text { prospectivo } \\
\text { e aberto }\end{array}$ & $\begin{array}{l}23 \text { de } \\
\text { fovereiro de } \\
2020 \text { a } 20 \text { de } \\
\text { março de } \\
2020\end{array}$ & 10 diss & $\begin{array}{l}\text { Pimeiro dis } \\
200 \mathrm{mg} \\
\text { intravenoso } \\
\text { e por nove } \\
\text { dias } 100 \mathrm{mg} \\
\text { intravenoso }\end{array}$ & $\begin{array}{l}\text { Pacientes com pheumonia } \\
\text { SARS-COV-2 }\end{array}$ & $\operatorname{Sim}$ & Sim & Näo & 35 \\
\hline $\begin{array}{l}\text { Remdesivir for the Trestment } \\
\text { of Covid-19- Final Repont }\end{array}$ & Beigel JHet al. & $\begin{array}{l}\text { Ensoio } \\
\text { elinico duplo- } \\
\text { cego } \\
\text { randomizad } \\
0\end{array}$ & $\begin{array}{l}21 \text { de } \\
\text { fevereso de } \\
2020 \text { a } 19 \text { de } \\
\text { abrit de } 2020\end{array}$ & 30 dies & $\begin{array}{l}\text { Primeiro dia } \\
200 \mathrm{mg} \text { a } \\
\text { restante } \\
\text { des das } \\
100 \mathrm{mg} \\
\text { txidia }\end{array}$ & $\begin{array}{l}\text { Pacientes adjitos } \\
\text { hosphasizados com Covid. } \\
19 \text { e com evidencia de } \\
\text { infocçbo do trato } \\
\text { respiratbeio inferior }\end{array}$ & Sim & Nào & $\begin{array}{l}\text { Sim, } 521 \\
\text { pacientes }\end{array}$ & 1062 \\
\hline $\begin{array}{l}\text { Remdesivir for } 5 \text { or } 10 \text { Deys } \\
\text { in Patients with Severe Cond- } \\
\qquad 19\end{array}$ & Goldman JD, *1 al & $\begin{array}{l}\text { Ensaio } \\
\text { clinico } \\
\text { randomizad } \\
\text { o, oberto, de } \\
\text { tase ill }\end{array}$ & $\begin{array}{l}6 \text { de março } \\
\text { de } 2020 \text { a } 28 \\
\text { de marça do } \\
2020\end{array}$ & 11 dias & $\begin{array}{l}\text { Primeiro dia } \\
200 \mathrm{mg} \text { e } \\
\text { restante } \\
\text { dos das } \\
100 \mathrm{mg} \\
\text { intravenoso }\end{array}$ & $\begin{array}{l}\text { Pacientes hosplasizados } \\
\text { com infecçáso confirmada } \\
\text { por SARS-CoV.2 }\end{array}$ & $\begin{array}{l}\text { Sim, mas sem } \\
\text { diterença } \\
\text { significativa }\end{array}$ & Năo & N5o & 367 \\
\hline
\end{tabular}

Fonte: Autores. 
Research, Society and Development, v. 10, n. 6, e37910615579, 2021

(CC BY 4.0) | ISSN 2525-3409 | DOI: http://dx.doi.org/10.33448/rsd-v10i6.15579

Tabela 5: Artigos selecionados sobre interferons.

\begin{tabular}{|c|c|c|c|c|c|c|c|c|c|c|}
\hline Artigo & Autor & $\begin{array}{l}\text { Tipo de } \\
\text { Estudo }\end{array}$ & $\begin{array}{l}\text { Periodo do } \\
\text { Estudo }\end{array}$ & $\begin{array}{l}\text { Tempo de } \\
\text { Tratamento }\end{array}$ & Dose & Tipo de Paciente & $\begin{array}{l}\text { Houve } \\
\text { melhora } \\
\text { clinica? }\end{array}$ & $\begin{array}{l}\text { Houve balé } \\
\text { de } \\
\text { mortalidade? }\end{array}$ & $\begin{array}{l}\text { Grupo } \\
\text { Controle }\end{array}$ & Qual on? \\
\hline $\begin{array}{l}\text { Subcitaneous } \\
\text { administration of interteron } \\
\text { beta-ta for COVvO-19 A } \\
\text { non-cantiroled prospective } \\
\text { trial }\end{array}$ & Faraneg, D et al. & $\begin{array}{l}\text { Estudo } \\
\text { peospectivo }\end{array}$ & $\begin{array}{l}1 \text { de março } \\
\text { de } 2020\end{array}$ & 10 das & 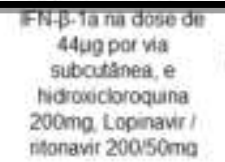 & $\begin{array}{l}\text { Paciertes maiores de } 18 \\
\text { anos com infecclato por } \\
\text { COMD-19 }\end{array}$ & Sim & Năo irtomado & NSo & 20 \\
\hline 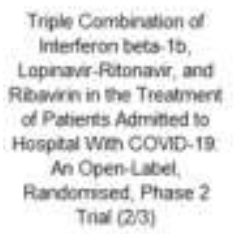 & Man, F et al: & $\begin{array}{l}\text { Estudo de fase } \\
\text { 1. open label } \\
\text { randomzado }\end{array}$ & $\begin{array}{l}10 \text { de } \\
\text { levereiro de } \\
2020 \text { a } 20 \text { de } \\
\text { maco de } \\
2020\end{array}$ & 14 dias & 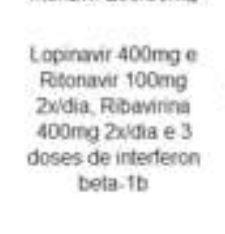 & $\begin{array}{l}\text { NEWS de pelo menos } 1 \\
\text { menos de } 14 \text { dias de } \\
\text { sintomas }\end{array}$ & Sim & Naso irformado & $\begin{array}{l}\text { Sim, } 41 \\
\text { pacientes }\end{array}$ & 80 \\
\hline $\begin{array}{l}\text { A Randemized Cinica } \\
\text { Trail of the Efficacy and } \\
\text { 5stety of interferon ph-1 a in } \\
\text { Trearment of Severe } \\
\text { COviD-19 } \\
\text { interferon-o2b spray }\end{array}$ & Ettat, 0 et al & $\begin{array}{l}\text { Estudo clinco } \\
\text { randomizado }\end{array}$ & $\begin{array}{l}29 \text { de } \\
\text { fevereiro de } \\
2020 \text { a } 3 \text { de } \\
\text { abrit de } 2020\end{array}$ & 14 dias & $\begin{array}{c}44 \text { ugimi irjetados SC } \\
3 \times \text { semrana por } 2 \\
\text { semanas }\end{array}$ & $\begin{array}{l}\text { Paciertes hosptaizados } \\
\text { con CovD. } 19 \text { grave }\end{array}$ & $\sin$ & Sim & $\begin{array}{l}\text { Sim, } 39 \\
\text { pacientes }\end{array}$ & 81. \\
\hline $\begin{array}{l}\text { whalatinn did not shorten } \\
\text { verus sheddry bine of } \\
\text { SARS.Cov. } 2 \text { in } \\
\text { hospotalired patients a } \\
\text { preiminary maxhed case. } \\
\text { control study }\end{array}$ & Shao, Ret at & $\begin{array}{l}\text { Estudo caso } \\
\text { controle }\end{array}$ & $\begin{array}{l}19 \text { de janesio } \\
\text { de } 2020 \text { a } 19 \\
\text { de fevereiro } \\
\text { de } 2020\end{array}$ & 7 das & $\begin{array}{l}\text { Soray de IFN-d2b } \\
\text { humano recombinante } \\
\text { na dosagem de } \\
100.000 u, 4 x 7 \text { dias }\end{array}$ & $\begin{array}{c}\text { Pacientes coctimados } \\
\text { por covo-19 }\end{array}$ & $\begin{array}{l}\text { nào } \\
\text { informado }\end{array}$ & Sim & $\begin{array}{c}\text { Sim } 36 \\
\text { pacientes }\end{array}$ & 104 \\
\hline $\begin{array}{l}\text { Interferon-acs Treatmert } \\
\text { for covD-19 (1/2) }\end{array}$ & Zhou, $Q$ ef at. & $\begin{array}{l}\text { Estudo } \\
\text { exploratónio năo } \\
\text { controlado }\end{array}$ & $\begin{array}{c}16 \text { de janeiro } \\
\text { de } 2020 \text { a } 20 \\
\text { fevereiro de } \\
2020\end{array}$ & 15 dias & $\begin{array}{l}\text { FN-ata-2D } 1 \mathrm{mi} \text { elou } \\
\text { Ahbidol } 100 \mathrm{mg}\end{array}$ & $\begin{array}{l}\text { Pacientes corfirmadose } \\
\text { hospitalizados no periodo }\end{array}$ & Sim & NSo irfomado & Năo & 7 \\
\hline 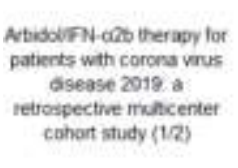 & $X_{u}, P$ et al. & $\begin{array}{l}\text { Estudo } \\
\text { manticentrico de } \\
\text { coorso } \\
\text { fetrospectivo }\end{array}$ & $\begin{array}{l}1 \text { de janeiro } \\
\text { de } 2020 \text { a } 1 \\
\text { de marco de } \\
2020\end{array}$ & 14 dias & $\begin{array}{c}\text { INF-afa2b } 5 \times 10(5) \text { ui } \\
\text { inalado } 2 \text { udia por } 10- \\
14 \text { dias e iNF sozinho } \\
\text { ou com artidol } \\
200 \mathrm{mg} \text { orai 3xidia por } \\
7.10 \text { dias }\end{array}$ & $\begin{array}{l}\text { Pacientes com pneumoria } \\
\text { sem vertlaçäo }\end{array}$ & inconclusivo & Nào irformado & Naิo & 141 \\
\hline 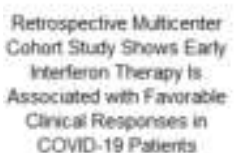 & Wang $N$ et al & $\begin{array}{l}\text { Estudo } \\
\text { mulicentro } \\
\text { retrospectivo }\end{array}$ & $\begin{array}{c}15 \text { de janevo } \\
\text { de } 2020 \text { a } 31 \\
\text { de marco de } \\
2020\end{array}$ & 8 dias & Näa informado & $\begin{array}{c}\text { Pacientes de CovD. } 19 \\
\text { com irtemaço maior ou } \\
\text { iguai a } 5 \text { dias e reg:stros } \\
\text { completos }\end{array}$ & Nas & Sim & $\begin{array}{l}\text { Sum } 122 \\
\text { pacientes }\end{array}$ & 446 \\
\hline
\end{tabular}

Fonte: Autores.

Tabela 6: Artigos selecionados sobre ruxolitinib.

\begin{tabular}{|c|c|c|c|c|c|c|c|c|c|c|}
\hline \multicolumn{11}{|c|}{ Ruxolitinib } \\
\hline Artigo & Autor & $\begin{array}{l}\text { Tlpo de } \\
\text { Estudo }\end{array}$ & $\begin{array}{l}\text { Periodo do } \\
\text { Estudo }\end{array}$ & $\begin{array}{l}\text { Tempo de } \\
\text { Tratamento }\end{array}$ & Dose & Tipo de Paciente & $\begin{array}{l}\text { Houve } \\
\text { meihora } \\
\text { clinica? }\end{array}$ & $\begin{array}{c}\text { douve baixa } \\
\text { de } \\
\text { mortalidade? }\end{array}$ & $\begin{array}{l}\text { Grupo } \\
\text { Controle }\end{array}$ & Qual on? \\
\hline $\begin{array}{l}\text { Purvitint in ireatment of } \\
\text { severe cotonavius dsease } \\
20+9 \text {;COVD-19) A } \\
\text { mulicenter, single-bind, } \\
\text { landomized contioled trial }\end{array}$ & Yang $C$. et al & $\begin{array}{l}\text { Esospectivo, } \\
\text { mulicentrico, } \\
\text { simples-cogo, } \\
\text { randornizado e } \\
\text { controlado de } \\
\text { tase ll }\end{array}$ & $\begin{array}{l}9 \text { de fevereiro } \\
\text { de } 2020 \text { a } 28 \\
\text { de fevereiro de } \\
2020\end{array}$ & 18 das & $5 \mathrm{mg}$ & $\begin{array}{l}\text { Paciertes entre } 18 \text { e } 75 \\
\text { anos com ComD-19 grave }\end{array}$ & Sim & Naso & $\begin{array}{l}\text { Sinn } 21 \\
\text { pacientes }\end{array}$ & 43 \\
\hline $\begin{array}{c}\text { Ruxolitinib Rapidy Reduces } \\
\text { Acute Respiratory Distress } \\
\text { Syndrome in CovD-19 } \\
\text { Oisease Analysis of Data } \\
\text { Colection From RESPIRE } \\
\text { Protocol }\end{array}$ & Ennco, $C$ et al & $\begin{array}{l}\text { Estudo } \\
\text { manicentrico, } \\
\text { retrospertivo }\end{array}$ & $\begin{array}{l}1 \text { de março de } \\
2020 \text { a } 1 \text { de } \\
\text { abeail de } 2020\end{array}$ & 14 das & $\begin{array}{l}20 \mathrm{mg} 2 \mathrm{zu} 4 \mathrm{sh} \\
\text { e } 10 \mathrm{mg} \text { Seng } \\
\text { 2uida }\end{array}$ & $\begin{array}{c}\text { Pacientes com sindrome } \\
\text { do descontonto respiratorio } \\
\text { apudo relacionado a } \\
\text { CovD-19 clisicamerte } \\
\text { progressiva }\end{array}$ & Sim & Räo: & Nào & 18 \\
\hline 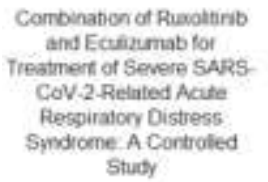 & Vaiertina, C ef al & $\begin{array}{l}\text { Estudo } \\
\text { cortrobado }\end{array}$ & $\begin{array}{l}1 \text { de março de } \\
2020 \text { a } 1 \text { de } \\
\text { abeil de } 2020\end{array}$ & 14 das & $\begin{array}{l}\text { Puxolinio } \\
10 \text { ing } 2 x i d i a ~ o \\
\text { Eculizumab } \\
900 \mathrm{mg}\end{array}$ & $\begin{array}{l}\text { Paciertes mavares de } 18 \\
\text { anos com dapnostico de } \\
\text { pnesumona e infectalu por } \\
\text { SARS.CoV. } 2 \text { confimado } \\
\text { por RT.PCR }\end{array}$ & Sim & Nabs & $\begin{array}{l}\text { Sim } 10 \\
\text { pacientes }\end{array}$ & 17 \\
\hline
\end{tabular}

Fonte: Autores. 
Research, Society and Development, v. 10, n. 6, e37910615579, 2021

(CC BY 4.0) | ISSN 2525-3409 | DOI: http://dx.doi.org/10.33448/rsd-v10i6.15579

Tabela 7: Artigos selecionados sobre corticosteroides.

\begin{tabular}{|c|c|c|c|c|c|c|c|c|c|c|}
\hline \multicolumn{11}{|c|}{ Corticosteroides } \\
\hline Artigo & Autor & Tipo de Estudo & $\begin{array}{l}\text { Periodo do } \\
\text { Estudo }\end{array}$ & $\begin{array}{l}\text { Tempo de } \\
\text { Tratamento }\end{array}$ & Dose & $\begin{array}{l}\text { Tipo de } \\
\text { Paciente }\end{array}$ & $\begin{array}{l}\text { Houve melhore } \\
\text { clinica? }\end{array}$ & $\begin{array}{l}\text { Houve baixa } \\
\text { de } \\
\text { mortalidade? }\end{array}$ & $\begin{array}{l}\text { Grupo } \\
\text { Controle }\end{array}$ & Qual on? \\
\hline $\begin{array}{l}\text { Conicosteroid treatrnent } \\
\text { of paterts with } \\
\text { coronavinus disease } \\
2019 \text { (covo-19) }\end{array}$ & Lei, $Z$ et al. & $\begin{array}{c}\text { Estudo } \\
\text { observacional }\end{array}$ & $\begin{array}{c}24 \text { de janeiro } \\
\text { de } 2020 \text { a } 24 \\
\text { de fevereiro de } \\
2020\end{array}$ & 5 dias & $40 \mathrm{eng}$ & $\begin{array}{l}\text { Pacientes } \\
\text { inlectados com } \\
\text { COViD-19 } \\
\text { agudo grave } 2 \\
\text { (SARS-CoV-2) }\end{array}$ & Sim & Năo informado & Năo & 31 \\
\hline $\begin{array}{l}\text { Corticosteroid therapy for } \\
\text { patents with COVi-19 } \\
\text { poneumonia a before- } \\
\text { after study }\end{array}$ & Firouze, B et al. & $\begin{array}{c}\text { Estudo } \\
\text { coservacional }\end{array}$ & $\begin{array}{l}3 \text { de marco de } \\
2020 \text { a } 14 \text { de } \\
\text { abril de } 2020\end{array}$ & 7 dias & $\begin{array}{l}200 \mathrm{mg} \\
\text { 20udia }\end{array}$ & $\begin{array}{l}\text { Pacientes cam } \\
\text { pneumonia por } \\
\text { Cond-19 }\end{array}$ & Sim & Sim & Sim & 319 \\
\hline $\begin{array}{l}\text { Ellicacy of } \\
\text { conticosteroids in non- } \\
\text { intersive care unt } \\
\text { patents with COVDD-19 } \\
\text { pneumona from the New } \\
\text { York Metropolitan region }\end{array}$ & Monil, M. et at & $\begin{array}{l}\text { Entudo de coonte } \\
\text { retrospectivo de } \\
\text { certro inico }\end{array}$ & $\begin{array}{l}16 \text { de marco de } \\
2020 \text { a } 30 \text { de } \\
\text { abnt de } 2020\end{array}$ & 5 dias & Bdeng & $\begin{array}{l}\text { Pacientes com } \\
\text { pneumonia por } \\
\text { Covid-19 }\end{array}$ & $\operatorname{sim}$ & $\operatorname{sim}$ & $\sin$ & 205 \\
\hline
\end{tabular}

Fonte: Autores.

Tabela 8: Artigo selecionado sobre heparina.

\begin{tabular}{|c|c|c|c|c|c|c|c|c|c|c|}
\hline \multicolumn{11}{|c|}{ Heparina } \\
\hline Artigo & Autor & Tipo de Estudo & $\begin{array}{l}\text { Periodo do } \\
\text { Estudo }\end{array}$ & $\begin{array}{l}\text { Tempo de } \\
\text { Tratamento }\end{array}$ & Dose & Tipo de Paciente & $\begin{array}{l}\text { Houve } \\
\text { melhora } \\
\text { clinica? }\end{array}$ & $\begin{array}{c}\text { Houve baixa } \\
\text { de } \\
\text { mortalidade? }\end{array}$ & $\begin{array}{l}\text { Grupo } \\
\text { Controle }\end{array}$ & Qual on? \\
\hline
\end{tabular}

Fonte: Autores.

Tabela 9: Artigos selecionados sobre ribavirina.

\begin{tabular}{|c|c|c|c|c|c|c|c|c|c|c|}
\hline \multicolumn{11}{|c|}{ Ribavirin } \\
\hline Artigo & Autor & Tipo de Estudo & $\begin{array}{l}\text { Periodo do } \\
\text { Estudo }\end{array}$ & $\begin{array}{l}\text { Tempo de } \\
\text { Tratamento }\end{array}$ & Dose & Thpo de Paciente & $\begin{array}{l}\text { Houve } \\
\text { melhora } \\
\text { clinica? }\end{array}$ & $\begin{array}{l}\text { Hotrve taitor } \\
\text { de } \\
\text { mortalidade? }\end{array}$ & $\begin{array}{c}\text { Grupo } \\
\text { Controle }\end{array}$ & Qual on? \\
\hline 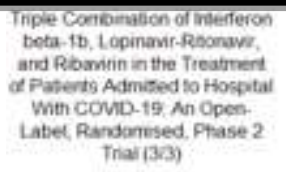 & $\operatorname{man} F$ es at & $\begin{array}{l}\text { Estudo de tase LI. } \\
\text { cpen label. } \\
\text { randonszado }\end{array}$ & $\begin{array}{l}10 \text { de fevereire } \\
\text { de } 2020 \text { a } 20 \\
\text { de maça de } \\
2020\end{array}$ & $14 d a s$ & 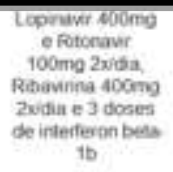 & $\begin{array}{c}\text { NEWS de pelo menus } 1 \\
\text { menos de } 14 \text { dias de } \\
\text { sinomas }\end{array}$ & $\operatorname{sim}$ & Maso informado & $\begin{array}{c}\operatorname{sim} 44 \\
\text { pacientes }\end{array}$ & 86 \\
\hline $\begin{array}{l}\text { The comesation betieen viral } \\
\text { cearance and bicchemsicat } \\
\text { odtcomes of } 94 \text { COVD-19 } \\
\text { rfected discharped patients } \\
\text { (2/2) }\end{array}$ & $\operatorname{sing} Y$ of al & $\begin{array}{l}\text { Esturdo } \\
\text { retrospectivo ae } \\
\text { certro ínico }\end{array}$ & $\begin{array}{l}11 \text { de jarecio de } \\
2020 \text { a } 4 \text { de } \\
\text { Bevereiro de } \\
2020\end{array}$ & 16 das & Năo informado & $\begin{array}{l}\text { Pacientes com CON10.19 } \\
\text { que receberam ata } \\
\text { hospitatar }\end{array}$ & $\operatorname{sim}$ & Nso irtomado & Näo & 94 \\
\hline 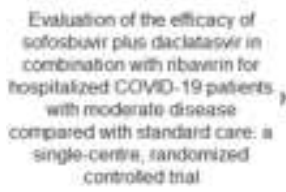 & Hamideh, $A$ et al & $\begin{array}{l}\text { Ensaso dinico } \\
\text { randomitado e } \\
\text { controlado sm um } \\
\text { ínco certro }\end{array}$ & $\begin{array}{l}20 \text { de musco de } \\
2020 \text { a s de } \\
\text { abeil ise } 2020\end{array}$ & 6 dias & 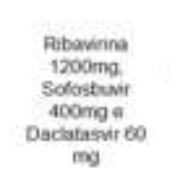 & $\begin{array}{l}\text { Pacientes cam mais de } 18 \\
\text { anos cam Covo- } 19 \\
\text { mederado }\end{array}$ & Incondervo & Nato intormado & $\begin{array}{c}\operatorname{sim}, 24 \\
\text { pacientes }\end{array}$ & 46 \\
\hline $\begin{array}{l}\text { Pebaninin therapy for severe } \\
\text { COVDD. } 19 \text { a fetvospective } \\
\text { cohart shidy }\end{array}$ & Tong. 8 is al. & $\begin{array}{l}\text { Estudo } \\
\text { unicentrico. } \\
\text { fetrospoctivo e } \\
\text { nfor randemizado }\end{array}$ & $\begin{array}{l}1 \text { de ianeuro de } \\
2000 \text { a } 1 \text { de } \\
\text { levereiro de } \\
2000\end{array}$ & 12 dias & $\begin{array}{c}\text { Rabaurina 500ng } \\
\text { 2vida }\end{array}$ & $\begin{array}{c}\text { Paciersos com conv-19 } \\
\text { grave }\end{array}$ & Sim & Năอ & $\begin{array}{c}\operatorname{sim} 71 \\
\text { pacientes }\end{array}$ & $\$ 15$ \\
\hline
\end{tabular}

Fonte: Autores. 


\section{Discussão}

A discussão do presente trabalho foi realizada separadamente para cada grupo de artigos que apresentam os estudos realizados com as diferentes classes terapêuticas já descritas nos resultados.

\subsection{Cloroquina e hidroxicloroquina}

Em relação à cloroquina e hidroxicloroquina, foram selecionados 14 artigos de acordo com os critérios de inclusão, sendo 3 (21,43\%) ensaios clínicos: um ensaio clínico multicêntrico aberto, randomizado e controlado; um ensaio clínico aberto não randomizado e um ensaio clínico randomizado controlado. Também tiveram 11 (78,57\%) estudos observacionais, sendo um estudo multicêntrico retrospectivo observacional; 6 estudos observacionais e 4 estudos retrospectivos. Alguns estudos apresentaram grupo controle para comparação, enquanto outros não forneceram ou não realizaram essa comparação.

A predominância de estudos observacionais e retrospectivos corrobora com a urgência e falta de recursos para ensaios clínicos, o que acarreta na utilização de dados de pacientes em tratamento.

Com relação ao número de pacientes analisados $(n)$, os trabalhos apresentaram grande variação, com $4(28,57 \%)$ artigos com $n$ menor que 100; 4 (28,57\%) artigos com $n$ entre 100 e 1000; 2 (14,28\%) artigos com $n$ entre 1001 e $2000 ; 2$ $(14,28 \%)$ artigos com $n$ entre 2001 e 3000 e 2 (14,28\%) artigos com $n$ maior que 3000. Vale ressaltar que o estudo realizado em 2020 por Mehra e colaboradores com $n$ de 96032 pacientes, e que informava não haver evidências nos benefícios do tratamento da cloroquina ou hidroxicloroquina, não foi incluído nesta revisão por ter sido removido rapidamente após sua publicação pela revista The Lancet.

Dos estudos selecionados, 3 (21,43\%) não apresentaram grupo controle, enquanto $11(78,57 \%)$ apresentaram. Com relação aos grupos controle, 7 (50\%) estudos utilizaram tratamento padrão ou outros tratamentos diversos como grupo controle, 1 (7,14\%) estudo utilizou lopinavir/ritonavir como grupo controle, 2 (14,28\%) artigos utilizaram lopinavir/ritonavir e tratamento padrão como controles e 1 (7,14\%) estudo utilizou combinações de azitromicina e hidroxicloroquina, apenas azitromicina, apenas hidroxicloroquina, todos com tratamento padrão associado, e o tratamento padrão sem a associação de azitromicina e hidroxicloroquina como grupo controle.

Ao analisar melhora clínica ou redução do tempo de redução de carga viral, $6(42,86 \%)$ dos estudos selecionados não apresentaram melhora significativa, enquanto 5 (35,71\%) estudos apresentaram melhora clínica em relação aos grupos controle e à literatura em estudos sem grupo controle. Em 3 (21,42\%) estudos não foram apresentaram dados com relação à melhora clínica dos pacientes ou comparação com a literatura.

Em relação à redução da taxa de mortalidade, 3 (21,42\%) estudos não apresentaram diferença relevante na taxa de mortalidade em comparação aos grupos controle, enquanto outros $3(21,42 \%)$ apresentaram redução das taxas de mortalidade e $8(57,14 \%)$ não apresentaram estas informações em seus estudos.

A falta de evidências de qualidade proporcionada pelas metodologias conflitantes e não eficientes, como ausência de grupo controle e " $n$ " pequeno em alguns estudos, além dos efeitos colaterais cardíacos consideráveis, especialmente em associação com a azitromicina, fazem com que o uso de hidroxicloroquina e cloroquina não seja recomendado como tratamento para a COVID-19, sendo seu uso recomendado apenas para a realização de ensaios clínicos, capazes de comprovar eficientemente sua eficácia ou ineficácia (Kashour, et al., 2020; WHO, 2020b).

\subsection{Tocilizumabe}

De acordo com os critérios de inclusão, foram triados 11 artigos sobre o tocilizumabe, sendo $3(27,27 \%)$ estudos observacionais, 2 (18,18\%) estudos prospectivos abertos e $6(54,54 \%)$ estudos retrospectivos. Destes, 6 (54,54\%) não apresentavam grupo controle, sendo que os outros $5(45,45 \%)$ o apresentavam. Dentre os grupos controle, 1 (9,09\%) estudo 
utilizou hidroxicloroquina, lopinavir/ritonavir e antibióticos; 1 (9,09\%) estudo utilizou hidroxicloroquina lopinavir/ritonavir, cefriaxone, azitromicina e enoxaparina; 2 (18,18\%) estudos utilizou pacientes que receberam qualquer outro tipo de tratamento que não tocilizumabe; $1(9,09 \%)$ estudo utilizou hidroxicloroquina, darunavir/ritonavir, antibióticos e heparina. Com respeito ao número de pacientes, houve $4(36,36 \%)$ artigos com $n$ menor que 50, $3(27,27 \%)$ artigos com o $n$ entre 50 e $99,3(27,27 \%)$ artigos com $n$ entre 100 e 215 e apenas $1(9,09 \%)$ artigo com o $n$ maior que 600.

Analisando a melhora clínica dos pacientes, foram encontradas melhoras no quadro clínico de pacientes em 9 $(81,18 \%)$ estudos, sendo que $2(18,18 \%)$ não encontraram diferença com relação ao grupo controle. Quando se diz respeito à taxa de mortalidade, $4(36,36 \%)$ estudos apresentaram diminuição da mesma, um deles apresentou diminuição apenas quando excluídos pacientes intubados, 2 estudos não observaram diferença na taxa de mortalidade e 4 (36,36\%) estudos não analisaram este parâmetro.

Considerando a tempestade de citocinas como uma das complicações mais expressivas da COVID-19, o tocilizumabe se apresentou como um fármaco promissor para seu tratamento. Porém, a falta de evidências de alta qualidade leva a acreditar que não há provas que sustentem a eficácia do tocilizumabe para o tratamento de casos raros de COVID-19, nos quais a tempestade de citocinas é clinicamente importante (Lan et al., 2020). Considerando a não confirmação atual de sua eficácia, além de efeitos colaterais como infecções secundárias, dores de cabeça e aumento de ALT, a OMS não recomenda o uso de tocilizumabe, com exceção para ensaios clínicos (WHO, 2020b).

\subsection{Lopinavir/ritonavir}

Foram selecionados 10 artigos sobre lopinavir/ritonavir, de acordo com os critérios de inclusão. Destes, foram triados 1 (10\%) estudo randomizado open-label, 1 (10\%) estudo de fase II open-label randomizado, 5 (50\%) estudos retrospectivos, $2(20 \%)$ estudos comparativos, 1 (10\%) estudo de coorte prospectivo longitudinal. Em relação ao número de pacientes, estão inclusos $2(20 \%)$ artigos com $n$ menor que 50, 4 (40\%) artigos com $n$ entre 50 e 100 e 4 (40\%) artigos com $n$ maior que 100. Considerando grupos controle, 7 (70\%) estudos os utilizam, enquanto 3 (30\%) não, sendo que entre eles, 2 (20\%) artigos utilizaram antibióticos e suporte vasopressor; 1 (10\%) artigo utilizou antibióticos e suporte vasopressor, além de terapia de hidrocortisona em pacientes que necessitavam de suporte ventilatório; 1 (10\%) artigo realizou a comparação da combinação arbidol e lopinavir/ritonavir em comparação com lopinavir/ritonavir sozinhos; 2 (20\%) artigos especificam apenas tratamento padrão, sem lopinavir/ritonavir; 1 (10\%) estudo comparou interferon alfa em conjunto com lopinavir/rinavir com interferon alfa em conjunto com lopinavir/ritonavir e ribavirina.

Ao analisar a melhora clínica, 7 (70\%) estudos afirmam possuir uma melhora clínica, sendo que $3(30 \%)$ deles não observaram melhora significante. Apenas um estudo investigou a taxa de mortalidade e não encontrou mudanças significativas.

As evidências sobre a eficácia de lopinavir/ritonavir são escassas, sendo o fármaco recomendado apenas sob supervisão, devido aos seus efeitos colaterais (Dehelean et al., 2020). De acordo com a falta de ensaios clínicos mais aprofundados, a OMS não recomenda o uso de lopinavir/ritonavir a não ser em ensaios clínicos (WHO, 2020b).

\subsection{Remdesivir}

Em relação ao remdesivir, foram selecionados 3 artigos de acordo com os critérios de inclusão. Quanto à metodologia de estudo, foram selecionados: 1 (33,33\%) estudo prospectivo (compassivo) e aberto, 1 (33,33\%) ensaio clínico duplo-cego, randomizado, 1 (33,33\%) ensaio clínico randomizado, aberto, de fase III. Com relação ao número de pacientes analisados, os estudos apresentaram muita variação, sendo 1 (33.33\%) estudo com 35, 1 (33,33\%) com 397 e 1 (33,33\%) com 1062. 
Dos estudos selecionados apenas $1(33,33 \%)$ apresenta grupo controle de 521 pacientes que receberam placebo, sendo que ambos os outros não possuem grupo controle.

No que diz respeito à melhora clínica, 2 dos 3 artigos $(66,66 \%)$ apresentaram melhora clínica nos sintomas. 1 (33.33\%) não mostrou diferença significativa na eficácia do uso do remdesivir, além disso, um dos artigos apresentou redução da taxa de mortalidade, sendo que os outros dois não apresentaram diferença.

Segundo os manuais da OMS, Clinical Management of COVID-19 e Therapeutics and COVID-19: living guideline, ambos de 2020, a administração de Remdesivir com adição do tratamento padrão não é recomendada, pois não há evidências sólidas de melhora em comparação com o tratamento padrão, com provável nenhum benefício. Caso haja a decisão de administração de remdesivir, o paciente deve apresentar funções renal e hepática não comprometidas (WHO, 2020b; WHO, 2020d)

\subsection{Interferons}

Considerando os interferons foram selecionados 7 artigos de acordo com os critérios de inclusão. Com respeito à metodologia, foram selecionados: 1 (14,28\%) estudo prospectivo, 1 (14,28\%) estudo fase II aberto randomizado, 1 (14,28\%) estudo clínico randomizado, 1 (14,28\%) estudo caso-controle, 1 (14,28\%) estudo exploratório não controlado, 1 (14,28\%) estudo retrospectivo multicêntrico de coorte, 1 (14,28\%) estudo multicêntrico retrospectivo.

Em relação ao número de pacientes analisados os estudos variaram, apresentando $4(57,14 \%)$ deles com $n$ menor que 100,2 (28,57\%) entre 100 e 150 , e $1(14,28 \%)$ com $n$ de 446.

Dos estudos selecionados $4(57,14 \%)$ apresentam grupo controle, enquanto $3(42,86 \%)$ não apresentam, destes grupos controle, 1 (14,28\%) estudo utilizou lopinavir/ritonavir; 1 (14,28\%) estudo variou entre hidroxicloroquina, lopinavir/ritonavir e azitromicina, corticoesteroides e imunoglobulinas intravenosas, dependendo da condição do paciente; 1 $(14,28 \%)$ artigo utilizou diversos tratamentos e categorizou como grupo controle o grupo que não recebeu interferons; 1 $(14,28 \%)$ estudo utilizou umifenovir ou lopinavir/ritonavir.

Com relação à melhora clínica, 5 dos 7 artigos (71,43\%) apresentaram melhora clínica. Porém 1 (14,28\%) deles apesar de apresentar melhora, mantém o período de disseminação do vírus. Os outros $2(28,57 \%)$ não apresentaram melhora clínica.

Devido aos estudos conflitantes e ensaios clínicos insuficientes, com adição de efeitos colaterais como rabdomiólise, o uso de interferons não é recomendado a não ser para estudos clínicos (Lam, Lombardi \& Ouanounou, 2020; Sanders et al., 2020; WHO, 2020b).

\subsection{Ruxolitinib}

Em relação ao ruxolitinib, foram selecionados 3 artigos de acordo com os critérios de inclusão. Quanto à metodologia de estudo, foram selecionados: 1 (33,33\%) estudo controlado, 1 (33,33\%) estudo prospectivo, multicêntrico, simples-cego, randomizado e controlado de fase II e 1(33,33\%) estudo multicêntrico, retrospectivo.

Dos estudos selecionados, 2 dos $3(66,66 \%)$ apresentaram grupo controle. Nenhum dos estudos apresentou baixa na taxa de mortalidade, porém ao analisar a melhora clínica, todos os 3 artigos apresentaram melhoras clínicas. 1 (33,33\%) dos estudos utilizou placebo como grupo controle, enquanto um estudo utilizou o melhor tratamento disponível no momento, a critério do estudo.

Apesar do número restrito de estudos, ruxolitinib e outros inibidores da JAK são fármacos promissores para o tratamento da COVID-19, sendo necessários estudos mais completos para produzir evidências mais sólidas (Rizk et al., 2020; Yeleswaram et al., 2020). 


\subsection{Corticosteroides}

Dos 4 artigos que analisaram corticosteroides, 2 (50\%) são estudos observacionais, 1 (25\%) é um estudo de coorte retrospectivo de centro único e 1 (25\%) é um estudo multicêntrico. Destes, apenas 1 (25\%) não apresenta grupo controle, que no caso dos estudos de corticosteroides são o tratamento padrão, sem o uso desta classe de fármaco. Considerando o número de pacientes, um estudo apresenta $n$ de 31, outro de 68, outro de 205 e outro de 319. Todos os estudos apresentaram melhora clínica ou redução da carga viral, 2 (50\%) estudos observaram uma baixa na taxa de mortalidade, sendo que outros 2 (50\%) não avaliaram este parâmetro.

Em relação aos fármacos estudados, 2 (50\%) artigos empregaram metilprednizolona, 1 (25\%) artigo empregou prednizolona ou metilprednizolona e 1 (25\%) artigo empregou metilprednisolona, prednisolona, prednisona, hidrocortisona ou dexametasona.

Devido à falta de evidências concretas, e possíveis complicações do paciente decorrentes do tratamento, a OMS não recomenda o tratamento de rotina por corticosteroides, sendo estes apenas aplicados quando houver a necessidade clínica desencadeada por outras condições (WHO, 2020b).

\subsection{Heparina}

Apenas um estudo sobre heparina foi selecionado. Este é um estudo observacional, com N de 2075 e com grupo controle, que não utilizou heparina. Nesse estudo foi possível observar melhora clínica e queda na taxa de mortalidade.

Segundo o protocolo de manejo clínico de pacientes com COVID-19 publicado pela OMS em 2020, a administração de heparina é recomendada para a profilaxia de tromboembolismo venoso, quando não houver contraindicações. Este não é um tratamento direto de COVID-19, porém tem potencial de evitar uma complicação fatal (WHO, 2020b).

\subsection{Ribavirina}

Sobre a ribavirina foram encontrados 5 estudos, sendo 1 (20\%) estudo de fase II aberto randomizado, 2 (40\%) estudos retrospectivos de centro único, 1 (20\%) ensaio clínico controlado randomizado e 1 (20\%) estudo aperto paralelo. O número de pacientes destes estudos varia entre 48 e 115, sendo que apenas um não apresenta grupo controle. Como grupo controle, 1 (20\%) estudo utilizou sofosbuvir e daclatasvir; 1 (20\%) estudo considerou grupo controle pacientes com tratamento padrão sem ribavirina; 1 (20\%) artigo comparou interferon beta 1b, lopinavir/ritonavir e ribavirina; 1 (20\%) recebeu hidroxicloroquina e lopinavir/ritonavir com ou sem ribavirina.

Ao analisar a melhora clínica dos pacientes, 4 (80\%) dos estudos observaram melhoras clínicas, sendo que um é inconclusivo. Quando avaliada a taxa de mortalidade, observamos que 3 (60\%) dos estudos não observaram este parâmetro. Além destes, um observou baixa na taxa de mortalidade, e outro não observou alterações.

Apesar de apresentar resultados promissores in vitro, a ribavirina ainda não apresentou resultados satisfatórios em estudos clínicos, tendo valor limitado quando utilizado com outros fármacos, especialmente interferons, porém com efeitos adversos importantes, como hepatotoxicidade e toxicidade hematológica (Lam, Lombardi \& Ouanounou, 2020; Sanders et al., 2020; Yousefi et al., 2020).

\section{Considerações Finais}

A rápida expansão da pandemia pelo mundo proporcionou uma necessidade de urgência na comunidade científica nunca antes vista. Enquanto há a pesquisa célere para uma vacina eficaz, diversas pessoas contraem a COVID-19 e necessitam de atendimento urgente. 
Como foi evidenciado no presente estudo, ainda não é definido o tratamento ideal para a COVID-19 e suas complicações. Com a urgência da produção rápida de resultados, foi possível observar que há grande dificuldade de produção de ensaios clínicos cego, duplo cego entre outros mais eficientes na real demonstração da eficácia dos tratamentos, fazendo com que a comunidade científica se restrinja principalmente a estudos retrospectivos e observacionais, que não são tão assertivos em seus resultados.

Apesar de alguns estudos apresentarem resultados favoráveis e fármacos promissores, são necessários ensaios clínicos para definir sua real eficácia, portanto, conclui-se, com base na observação dos estudos, que ainda não há um tratamento eficaz para a COVID-19, sendo extremamente crucial a aplicação de medidas preventivas, a fim de evitar o impacto da doença na população.

\section{Referências}

Ahn, D.-G., Shin, H.-J., Kim, M.-H., Lee, S., Kim, H.-S., Myoung, J., Kim, B.-T., \& Kim, S.-J. (2020) Current Status of Epidemiology, Diagnosis, Therapeutics, and Vaccines for Novel Coronavirus Disease 2019 (COVID-19). Journal Of Microbiology and Biotechnology, 30 (3), 313-324. doi: http://dx.doi.org/10.4014/jmb.2003.03011.

Antinori, S., Cossu, M. V., Ridolfo, A. L., Rech, R., Bonazzetti, C., Pagani, G., . . Castelli, A. (2020). Compassionate remdesivir treatment of severe Covid19 pneumonia in intensive care unit (ICU) and Non-ICU patients: clinical outcome and differences in post-treatment hospitalisation status. Pharmacological Research, (158), 1-6. doi: http://dx.doi.org/10.1016/j.phrs.2020.104899.

Arshad, S., Kilgore, P., Chaudhry, Z. S., Jacobsen, G., Wang, D. D., Huitsing, K., . . . Mckinnon, J. E. (2020). Treatment with hydroxychloroquine, azithromycin, and combination in patients hospitalized with COVID-19. International Journal of Infectious Diseases, (97), 396-403. doi: http://dx.doi.org/10.1016/j.ijid.2020.06.099.

Asakura, H., \& Ogawa, H. (2021). COVID-19-associated coagulopathy and disseminated intravascular coagulation. International journal of hematology, 113(1), 45-57. doi: https://doi.org/10.1007/s12185-020-03029-y

Ayerbe, L., Risco, C., \& Ayis, S. (2020). The association between treatment with heparin and survival in patients with Covid-19. Journal Of Thrombosis and Thrombolysis, 50 (2), 298-301. doi: http://dx.doi.org/10.1007/s11239-020-02162-z.

Bai, Y., Yao, L., Wei, T., Tian, F., Jin, D.-Y., Chen, L., \& Wang, M. (2020) Presumed Asymptomatic Carrier Transmission of COVID-19. Jama, 323 (14), 1406-1407. doi: http://dx.doi.org/10.1001/jama.2020.2565.

Bani-Sadr, F., Hentzien, M., Pascard, M., N'guyen, Y., Servettaz, A., Andreoletti, L, Kanagaratnam, L., \& Jolly, D. (2020). Corticosteroid therapy for patients with COVID-19 pneumonia: a before::after study. International Journal of Antimicrobial Agents, 56(2), 1-4. doi: http://dx.doi.org/10.1016/j.ijantimicag.2020.106077.

Beigel, J. H., Tomashek, K. M., Dodd, L. E., Mehta, A. K., Zingman, B. S., Kalil, A. C., . . Kline, S. (2020). Remdesivir for the Treatment of Covid-19 Final Report. New England Journal of Medicine, 383 (19), 1813-1826. doi: http://dx.doi.org/10.1016/j.ijantimicag.2020.106077.

Campochiaro, C., Della-Torre, E., Cavalli, G., Luca, G., Ripa, M., Boffini, N., . . Ruggeri, A. (2020). Efficacy and safety of tocilizumab in severe COVID-19 patients: a single-centre retrospective cohort study. European Journal of Internal Medicine, 76 (1), 43-49. doi: http://dx.doi.org/10.1016/j.ejim.2020.05.021.

Cao, Y., Wei, J., Zou, L., Jiang, T., Wang, G., Chen, L., . . . Wang, N. (2020). Ruxolitinib in treatment of severe coronavirus disease 2019 (COVID-19): a multicenter, single-blind, randomized controlled trial. Journal Of Allergy and Clinical Immunology, 146 (1), 137-146. doi: http://dx.doi.org/10.1016/j.jaci.2020.05.019.

Capochiani, E.; Frediani, B.; Iervasi, G.; Paolicchi, A.; Sani, S.; Roncucci, P., . . Carrara, D. (2020). Ruxolitinib Rapidly Reduces Acute Respiratory Distress Syndrome in COVID-19 Disease. Analysis of Data Collection from RESPIRE Protocol. Frontiers In Medicine, 7, (1), 1-9. doi: http://dx.doi.org/10.1016/j.jaci.2020.05.019.

Catteau, L., Dauby, N., Montourcy, M., Bottieau, E., Hautekiet, J., Goetghebeur, E., . . Wyndham-Thomas, C. (2020). Low-dose hydroxychloroquine therapy and mortality in hospitalised patients with COVID-19: a nationwide observational study of 8075 participants. International Journal of Antimicrobial Agents, 56 (4), 106144-106153. doi: http://dx.doi.org/10.1016/j.ijantimicag.2020.106144.

Chan, J. F.-W., Yuan, S., Kok, K.-H, To, K. K.-W., Chu, H., Yang, J., . . Poon, R. W. S. (2020). A familial cluster of pneumonia associated with the 2019 novel coronavirus indicating person-to-person transmission: a study of a family cluster. The Lancet, 395 (10223), 514-523. doi: http://dx.doi.org/10.1016/s0140-6736(20)30154-9.

Conrozier, T., Lohse, A., Balblanc, J. C., Dussert, P., Royer, P. Y., Bossert, M., . . Zayet, S. (2020). Biomarker variation in patients successfully treated with tocilizumab for severe coronavirus disease 2019 (COVID-19): results of a multidisciplinary collaboration. Clinical And Experimental Rheumatology, 4 (38) $742-747$.

Dastan, F., Nadji, S. A., Saffaei, A., Marjani, M., Moniri, A., Jamaati, H., . . Varahram, M. (2020). Subcutaneous administration of interferon beta-1a for COVID-19: a non-controlled prospective trial. International Immunopharmacology, 85, 1-5. doi: http://dx.doi.org/10.1016/s0140-6736(20)30154-9. 
Davoudi-Monfared, E., Rahmani, H., Khalili, H., Hajiabdolbaghi, M., Salehi, M., Abbasian, L., Kazemzadeh, H., \& Yekaninejad, M. S. (2020). A Randomized Clinical Trial of the Efficacy and Safety of Interferon $\beta-1 \mathrm{a}$ in Treatment of Severe COVID-19. Antimicrobial Agents and Chemotherapy, 64 (9), 1-14. doi: http://dx.doi.org/10.1128/aac.01061-20.

Dehelean, C. A., Lazureanu, V., Coricovac, D., Mioc, M., Oancea, R., Marcovici, I., . . Cretu, O. (2020). SARS-CoV-2: repurposed drugs and novel therapeutic approaches.: insights into chemical structure.: biological activity and toxicological screening. Journal Of Clinical Medicine, 9 (7), 2084-2094. doi: http://dx.doi.org/10.3390/jcm9072084.

Esakandari, H., Nabi-Afjadi, M., Fakkari-Afjadi, J., Farahmandian, N., Miresmaeili, S. M. \&, Bahreini, E. (2020). A comprehensive review of COVID-19 characteristics. Biological Procedures Online, 22 (1), 1-10. doi: http://dx.doi.org/10.3390/jcm9072084.

Eslami, G., Mousaviasl, S., Radmanesh, E., Jelvay, S., Bitaraf, S., Simmons, B., . . Freeman, J. (2020). The impact of sofosbuvir/daclatasvir or ribavirin in patients with severe COVID-19. Journal Of Antimicrobial Chemotherapy, 75 (11), 3366-3372. doi: http://dx.doi.org/10.3390/jcm9072084.

Esposito, S., Noviello, S., \& Pagliano, P. (2020). Update on treatment of COVID-19: ongoing studies between promising and disappointing results. Infezmed, $2(28), 198-211$.

Fehr, A. R., \& Perlman, S. (2015). Coronaviruses: an overview of their replication and pathogenesis. Coronaviruses, 1-23. doi: http://dx.doi.org/10.3390/jcm9072084.

Gao, G., Wang, A., Wang, S., Qian, F., Chen, M., Yu, F., . . . Zhao, T. (2020). A retrospective evaluation on the efficacy of Lopinavir/ritonavir and chloroquine to treat non-severe COVID-19 patients. Jaids Journal of Acquired Immune Deficiency Syndromes, $239-243$. doi: http://dx.doi.org/10.1097/qai.0000000000002452.

Gautret, P., Lagier, J.C., Parola, P., Hoang, V. T., Meddeb, L., Sevestre, J., . . Amrane, S. (2020). Clinical and microbiological effect of a combination of hydroxychloroquine and azithromycin in 80 COVID-19 patients with at least a six-day follow up: a pilot observational study. Travel Medicine And Infectious Disease, 34, 101663-101673. doi: http://dx.doi.org/10.1097/qai.0000000000002452.

Gautret, P, Lagier, J. C. J, Parola, P., Hoang, V. T., Meddeb, L., Mailhe, M., . . Vieira, V. E. (2020). Hydroxychloroquine and azithromycin as a treatment of COVID-19: results of an open-label non-randomized clinical trial. International Journal Of Antimicrobial Agents, 56 (1), 105949-105963. doi: http://dx.doi.org/10.1097/qai.0000000000002452.

Geleris, J., Sun, Y., Platt, J., Zucker, J., Baldwin, M., Hripcsak, G., . . Barr, R. G. (2020). Observational Study of Hydroxychloroquine in Hospitalized Patients with Covid-19. New England Journal of Medicine, 382 (25), 2411-2418. doi: http://dx.doi.org/10.1056/nejmoa2012410.

Giudice, V., Pagliano, P., Vatrella, A., Masullo, A., Poto, S., Polverino, B. M., . . Vitale, C. (2020). Combination of Ruxolitinib and Eculizumab for Treatment of Severe SARS-CoV-2-Related Acute Respiratory Distress Syndrome: a controlled study. Frontiers In Pharmacology, 11, (1), 1-6. doi: http://dx.doi.org/10.3389/fphar.2020.00857.

Goldman, J. D., Lye, D. C. B., Hui, D. S. Marks, K. M.; Bruno, R., Montejano, R., . . Nahass, R. G. (2020). Remdesivir for 5 or 10 Days in Patients with Severe Covid-19. New England Journal Of Medicine, 383 (19), 1827-1837. doi: https://doi.org/10.1056/NEJMoa2015301.

Guo, Y.-R., Cao, Q.-D., Hong, Z.-S., Tan, Y.-Y., Chen, S.-D., Jin, H.-J., . .YYan, Y. (2020). The origin, transmission and clinical therapies on coronavirus disease 2019 (COVID-19) outbreak - an update on the status. Military Medical Research, 7 (1) 1-10. doi: https://doi.org/10.1186/s40779-020-00240-0.

Hao, S.-R., Yan, R., Zhang, S.-Y., Lian, J.-S., Cai, H., Zhang, X.-L., . . Yu, G.-D. (2020). Interferon- $\alpha 2 b$ spray inhalation did not shorten virus shedding time of SARS-CoV-2 in hospitalized patients: a preliminary matched case-control study. Journal Of Zhejiang University-Science B, 21 (8), 628-636. doi: https://doi.org/10.1631/jzus.B2000211.

Huang, C., Wang, Y., Li, X., Ren, L., Zhao, J., Hu, Y., . . Gu, X. (2020). Clinical features of patients infected with 2019 novel coronavirus in Wuhan, China. The Lancet, 395 (10223), 497-506. doi: https://doi.org/10.1016/S0140-6736(20)30183-5.

Huang, M., Tang, T., Pang, P., Li, M., Ma, R., Lu, J., . . Liang, J. (2020). Treating COVID-19 with Chloroquine. Journal Of Molecular Cell Biology, 12 (4) 322-325. doi: https://doi.org/10.1093/jmcb/mjaa014.

Hung, I. F.-N., Lung, K.-C., Tso, E. Y.-K., Liu, R., Chung, T. W.-H., Chu, M.-Y., . . Tam, A. R. (2020). Triple combination of interferon beta-1b, lopinavir-ritonavir, and ribavirin in the treatment of patients admitted to hospital with COVID-19: an open-label, randomised, phase 2 trial. The Lancet, 395 (10238), 1695-1704. doi: https://doi.org/10.1016/S0140-6736(20)31042-4.

Ip, A., Berry, D. A., Hansen, E., Goy, A. H., Pecora, A. L., Sinclaire, B. A., . . Berry, N. S. (2020). Hydroxychloroquine and tocilizumab therapy in COVID19 patients-An observational study. Plos One, 15 (8), 1-19. doi: https://doi.org/10.1371/journal.pone.0237693

Kasgari, H. A., Moradi, S., Shabani, A. M., Babamahmoodi, F., Badabi, A. R. D., Davoudi, L., . . Merat, S. (2020). Evaluation of the efficacy of sofosbuvir plus daclatasvir in combination with ribavirin for hospitalized COVID-19 patients with moderate disease compared with standard care: a single-centre, randomized controlled trial. Journal Of Antimicrobial Chemotherapy, 75 (11), 3373-3378. doi: https://doi.org/10.1093/jac/dkaa332.

Kashour, Z., Riaz, M., Garbati, M., Aldosary, O., Tlayjeh, H., Gerberi, D., Murad, M. H., . . . Imad; M. (2020). Efficacy of chloroquine or hydroxychloroquine in COVID-19 patients: a systematic review and meta-analysis. Journal Of Antimicrobial Chemotherapy, 1 (1), 1-13. doi: https://doi.org/10.1093/jac/dkaa403.

Klopfenstein, T., Zayet, S., Lohse, A., Balblanc, J. C., Badie, J., Royer, P. Y., . . . Bossert, M. (2020). Tocilizumab therapy reduced intensive care unit admissions and/or mortality in COVID-19 patients. Médecine Et Maladies Infectieuses, 50 (5) 397-400. Doi: https://doi.org/10.1016/j.medmal.2020.05.001.

Lam, S., Lombardi, A., \& Ouanounou, A. (2020). COVID-19: a review of the proposed pharmacological treatments. European Journal of Pharmacology, 886 (1), 1-10. doi: https://doi.org/10.1016/j.ejphar.2020.173451.

Lan, S.-H., Lai, C.-C, Huang, H.-T., Chang, S.-T., Lu, L.-C., \& Hsueh, P.-R. (2020). Tocilizumab for severe COVID-19: a systematic review and metaanalysis. International Journal of Antimicrobial Agents, 56 (3), 106103-10615. doi: https://doi.org/10.1016/j.ijantimicag.2020.106103. 
Lecronier, M., Beurton, A., Burrel, S., Haudebourg, L., Deleris, R.., Marec, J. L., . . . Mora, P. (2020). Comparison of hydroxychloroquine, lopinavir/ritonavir, and standard of care in critically ill patients with SARS-CoV-2 pneumonia: an opportunistic retrospective analysis. Critical Care, 24 (1), 1-9. doi: https://doi.org/10.1186/s13054-020-03117-9.

Letko, M., Marzi, A., \& Munster, V. (2020). Functional assessment of cell entry and receptor usage for SARS-CoV-2 and other lineage B betacoronaviruses. Nature Microbiology, 5 (4), 562-569. doi: https://doi.org/10.1038/s41564-020-0688-y.

Levy, C., Lassailly, G., Parmentier, E., Duburcq, T., Mathurin, P., \& Poissy, J. (2020). Caution With the Use of Lopinavir/Ritonavir in Severely Ill Patients for the Treatment of SARS-CoV-2: a report of severe jaundice. American Journal of Gastroenterology, 115 (10), 1716-1718. doi: https://doi.org/10.14309/ajg.0000000000000828.

Li, W., Shi, Z., Yu, M., Ren, W., Smith, C., Epstein, J. H., Wangd, H., \& Crameri, Gary. (2005). Bats Are Natural Reservoirs of SARS-Like Coronaviruses. Science, 310 (5748) 676-679. doi: https://doi.org/10.1126/science.1118391.

Li, Y., Zhou, X., Li, T.; Chan, S., Yu, Y., Ai, J.-W., . . Zhu, L. Corticosteroid prevents COVID-19 progression within its therapeutic window: a multicentre, proof-of-concept, observational study. Emerging Microbes \& Infections, 9, (1) 1869-1877. doi: https://doi.org/10.1080/22221751.2020.1807885.

Lovato, A., Filippis, C., \& Marioni, G. (2020). Upper airway symptoms in coronavirus disease 2019 (COVID-19). American Journal Of Otolaryngology, 41 (3) 102474-102486. doi: https://doi.org/10.1016/j.amjoto.2020.102474.

Lu, R., Zhao, X., Li, J., Niu, P., Yang, B., Wu, H., . . Zhu, N. (2020). Genomic characterisation and epidemiology of 2019 novel coronavirus: implications for virus origins and receptor binding. The Lancet, 395 (10224), 565-574. doi: https://doi.org/10.1016/s0140-6736(20)30251-8.

Luo, P., Liu, Y., Qiu, L., Liu, X., Liu, D., \& Li, J. (2020). Tocilizumab treatment in COVID-19: a single center experience. Journal Of Medical Virology, 92 (7), 814-818. doi: https://doi.org/10.1002/jmv.2580.

Mahévas, M., Tran, V. T., Roumier, M., Chabrol, A., Paule, R., Guillaud, C., . . Lescure, F. X. (2020). Clinical efficacy of hydroxychloroquine in patients with covid-19 pneumonia who require oxygen: observational comparative study using routine care data. Bmj, $1844-1856$. doi: https://doi.org/10.1136/bmj.m1844.

Majmundar, M., Kansara, T., Lenik, J. M., Park, H., Ghosh, K., Doshi, R., . . Chaudhari, S. (2020). Efficacy of corticosteroids in non-intensive care unit patients with COVID-19 pneumonia from the New York Metropolitan region. Plos One, 15 (9) 1-14. doi: https://doi.org/10.1371/journal.pone.0238827.

Mikulska, M., Nicolini, L. A., Signori, A., Biagio, A., Sepulcri, C., Russo, C., . . Giacobbe, D. R. (2020). Tocilizumab and steroid treatment in patients with COVID-19 pneumonia. Plos One, 15, (8) 1-16. doi: https://doi.org/10.1371/journal.pone.0237831.

Million, M., Lagier, J. C., Gautret, P., Colson, P., Fournier, P. E., Amrane, S., . . Doudier, B. (2020). Early treatment of COVID-19 patients with hydroxychloroquine and azithromycin: a retrospective analysis of 1061 cases in marseille, france. Travel Medicine And Infectious Disease, 35, 101738101747. doi: https://doi.org/10.1016/j.tmaid.2020.101738.

Morena, V., Milazzo, L., Oreni, L., Bestetti, G., Fossali, T., Bassoli, C., . . Ballone, E. (2020). Off-label use of tocilizumab for the treatment of SARS-CoV-2 pneumonia in Milan, Italy. European Journal Of Internal Medicine 76, 36-42. doi: https://doi.org/10.1016/j.ejim.2020.05.011.

Mulangu, S., Dodd, L. E., Davey, R. T., Mbaya, O. T., Proschan, M., Mukadi, D., . . Ibanda, A. (2019). A Randomized, Controlled Trial of Ebola Virus Disease Therapeutics. New England Journal Of Medicine, 381 (24), 2293-2303. doi: https://doi.org/10.1056/NEJMoa1910993.

Nittari, G., Pallotta, G., Amenta, F., \& Tayebati, S. K. (2020). Current pharmacological treatments for SARS-COV-2: a narrative review. European Journal of Pharmacology, 882, 173328-173339. doi: https://doi.org/10.1016/j.ejphar.2020.173328.

Ren, L.-L., Wang, Y.-M., Wu, Z.-Q., Xiang, Z.-C., Guo, L., Xu, T., . . Li, X.-W. (2020). Identification of a novel coronavirus causing severe pneumonia in human. Chinese Medical Journal, 133 (9), 1015-1024. doi: https://doi.org/10.1097/CM9.0000000000000722

Rizk, J. G., Kalantar-Zadeh, K., Mehra, M. R.., Lavie, C. J., Rizk, Y., \& Forthal, D. N. (2020). Pharmaco-Immunomodulatory Therapy in COVID-19. Drugs, 80, (13) 1267-1292. doi: https://doi.org/10.1007/s40265-020-01367-z

Rojas-Marte, G., Khalid, M., Mukhtar, O., Hashmi, A. T., Waheed, M., Ehrlich, S., . . Malyshev, Y. (2020). Outcomes in patients with severe COVID-19 disease treated with tocilizumab: a case controlled study. Qjm: An International Journal of Medicine, 113 (8) 546-550. doi: https://doi.org/10.1093/qjmed/hcaa206

Sanders, J. M., Monogue, M. L., Jodlowski, T. Z., \& Cutrell, J. B. (2020). Pharmacologic Treatments for Coronavirus Disease 2019 (COVID-19): A Review. JAMA, 323(18), 1824-1836. doi: https://doi.org/10.1001/jama.2020.6019

Satlin, M. J., Goyal, P., Magleby, R., Maldarelli, G. A., Pham, K., Kondo, M., . . . Choi, J. J. (2020). Safety, tolerability, and clinical outcomes of hydroxychloroquine for hospitalized patients with coronavirus 2019 disease. Plos One, 15, (7) 1-14. doi: https://doi.org/10.1371/journal.pone.0236778

Schrezenmeier, E., \& Dörner, T. (2020). Mechanisms of action of hydroxychloroquine and chloroquine: implications for rheumatology. Nature Reviews Rheumatology, 16 (3), 155-166. doi: https://doi.org/10.1038/s41584-020-0372-x.

Sciascia, S., Aprà, F., Baffa, A., Baldovino, S., Boaro, D., Boero, R., . . Rossi, D. (2020). Pilot prospective open, single-arm multicentre study on off-label use of tocilizumab in patients with severe COVID-19. Clinical And Experimental Rheumatology, 38, (3), 529-532.

Tang, W.; Cao, Z.; Han, M.; Wang, Z.; Chen, J.; Sun, W.; Wu, Y.; Xiao, W.; Liu, S. \& Chen, E. (2020). Hydroxychloroquine in patients with mainly mild to moderate coronavirus disease 2019: open label, randomised controlled trial. Bmj, 1849 (369), 1-11. doi: https://doi.org/10.1136/bmj.m1849.

Tong, S., Su, Y., Yu, Y., Wu, C., Chen, J., Wang, S., \& Jiang, J. (2020). Ribavirin therapy for severe COVID-19: a retrospective cohort study. International Journal Of Antimicrobial Agents, 56 (3) 1-13. doi: https://doi.org/10.1016/j.ijantimicag.2020.106114. 
Toniati, P., Piva, S., Cattalini, M., Garrafa, E., Regola, F., Castelli F., . . . Beindorf, E. A. (2020). Tocilizumab for the treatment of severe COVID-19 pneumonia with hyperinflammatory syndrome and acute respiratory failure: a single center study of 100 patients in brescia, italy. Autoimmunity Reviews, 19 (7) 1-6. doi: https://doi.org/10.1016/j.autrev.2020.102568.

Tortorici, M. A., \& Veesler, D. (2019). Structural insights into coronavirus entry. Advances In Virus Research, p. 93-116. doi: https://doi.org/10.1016/bs.aivir.2019.08.002.

Vijayvargiya, P., Garrigos, Z. E., Almeida, N. E. C., Gurram, P. R., Stevens, R. W., \& Razonable, R. R. (2020). Treatment Considerations for COVID19. Mayo Clinic Proceedings, 95 (7), 1454-1466. doi: https://doi.org/10.1016/j.mayocp.2020.04.027.

Vincent, M. J., Bergeron, E., Benjannet, S, Erickson, B. R, Rollin, P., Ksiazek, T. G., Seidah, N. G., \& Nichol, S. T. (2005). Chloroquine is a potent inhibitor of SARS coronavirus infection and spread. Virology Journal, 69 (1), 1-10. doi: https://doi.org/10.1186/1743-422X-2-69.

Wan, S., Yi, Q., Fan, S., Lu., J., Zhang, X., Guo, L., . . . Yi, Z. (2020). Characteristics of lymphocyte subsets and cytokines in peripheral blood of 123 hospitalized patients with 2019 novel coronavirus pneumonia (NCP). Medrxiv, 1-13. doi: https://doi.org/10.1101/2020.02.10.20021832.

Wang, D., Hu, B., Hu, C., Zhu, F., Liu, X., Zhang, J., . . . Xiong, Y. (2020). Clinical Characteristics of 138 Hospitalized Patients With 2019 Novel Coronavirus-Infected Pneumonia in Wuhan, China. Jama, 323 (11), 1061-1073. doi: https://doi.org/10.1001/jama.2020.1585.

Wang, M., Cao, R., Zhang, L., Yang, X., Liu, J., Xu, M., . . Xiao, G. (2020). Remdesivir and chloroquine effectively inhibit the recently emerged novel coronavirus (2019-nCoV) in vitro. Cell Research, 30 (3), 269-271. doi: https://doi.org/10.1038/s41422-020-0282-0.

Wang, N., Zhan, Y., Zhu, L., Hou, Z., Liu, F., Song, P., . . . Wan, D. (2020). Retrospective Multicenter Cohort Study Shows Early Interferon Therapy Is Associated with Favorable Clinical Responses in COVID-19 Patients. Cell Host \& Microbe, 28 (3), 455-464. doi: https://doi.org/10.1016/j.chom.2020.07.005

World Health Organization. (2020a). WHO Coronavirus Disease (COVID-19) Dashboard. Recuperado de https://covid19.who.int/table

World Health Organization. (2020b). Clinical management of COVID-19. Recuperado de https://www.who.int/publications/i/item/clinical-management-ofcovid-19.

World Health Organization. (2020c). WHO Director-General's opening remarks at the media briefing on COVID-19 - 11 March 2020 . Recuperado de https://www.who.int/dg/speeches/detail/who-director-general-s-opening-remarks-at-the-media-briefing-on-covid-19---11-march-2020

World Health Organization. (2020d). Therapeutics and COVID-19: living guideline. Recuperado de https://www.who.int/publications/i/item/therapeutics-andcovid-19-living-guideline.

Xu, P., Huang, J., Fan, Z., Huang, W., Qi, M., Lin, X., Song, W., \& Yi, L. (2020). Arbidol/IFN- $\alpha 2 b$ therapy for patients with corona virus disease 2019: a retrospective multicenter cohort study. (2020). Microbes And Infection, 22 (4-5), 200-205. doi: http://dx.doi.org/10.1016/j.micinf.2020.05.012.

Xu, X., Han, M., Li, T., Sun, W., Wang, D., Fu, B., . . Li, X. (2020). Effective treatment of severe COVID-19 patients with tocilizumab. Proceedings Of The National Academy Of Sciences, 117 (20), 10970-10975. doi: http://dx.doi.org/10.1073/pnas.2005615117.

Yan, D., Liu, X.-Y., Zhu, Y.-N., Huang, L., Dan, B.-T., Zhang, G.-J., \& Gao, Y.-H. (2020). Factors associated with prolonged viral shedding and impact of lopinavir/ritonavir treatment in hospitalised non-critically ill patients with SARS-CoV-2 infection. European Respiratory Journal, 56 (1), 1-9.doi: https://doi.org/10.1183/13993003.00799.

Yeleswaram, S., Smith, P., Burn, T., Covington, M., Juvekar, A., Li, Y., Squier, P., \& Langmuir, P. (2020). Inhibition of cytokine signaling by ruxolitinib and implications for COVID-19 treatment. Clinical Immunology, 218 (1) 108517-108526. doi: http://dx.doi.org/10.1016/j.clim.2020.108517.

Yousefi, B., Valizadeh, S., Ghaffari, H., Vahedi, A., Karbalaei, M., \& Eslami, M. (2020). A global treatments for coronaviruses including COVID-19. Journal Of Cellular Physiology, 235 (12), 9133-9142. doi: http://dx.doi.org/10.1002/jcp.29785.

Yuan, J., Zou, R., Zeng, L., Kou, S., Lan, J., Li, X., . . Tang, S. (2020). The correlation between viral clearance and biochemical outcomes of 94 COVID-19 infected discharged patients. Inflammation Research, 69 (6), 599-606. doi: http://dx.doi.org/10.1007/s00011-020-01342-0.

Yuen, K.-S., Ye, Z.-W., Fung, S.-Y., Chan, C.-P., \& Jin, D.-Y. (2020). SARS-CoV-2 and COVID-19: the most important research questions. Cell \& Bioscience, 10 (1), 1-5. doi: http://dx.doi.org/10.5694/mja2.50577.

Zha, L., Li, S., Pan, L., Tefsen, B., Li, Y., French, N., . . . Villanueva, E. V. (2020). Corticosteroid treatment of patients with coronavirus disease 2019 (COVID -19). Medical Journal Of Australia, 212 (9), 416-420. doi: http://dx.doi.org/10.5694/mja2.50577.

Zhang, W., Zhao, Y., Zhang, F., Wang, Q., Li, T., Liu, Z, . . Yan, X. (2020). The use of anti-inflammatory drugs in the treatment of people with severe coronavirus disease 2019 (COVID-19): the perspectives of clinical immunologists from china. Clinical Immunology, 214, 108393-108404. doi: http://dx.doi.org/10.1016/j.clim.2020.108393.

Zhou, Q., Chen, V., Shannon, C. P., Wei, X.-S., Xiang, X., Wang, X., . . . Fish, E. N. (2020). Interferon- $\alpha 2 b$ Treatment for COVID-19. Frontiers In Immunology, 11, (1), 1-6. doi: http://dx.doi.org/10.3389/fimmu.2020.01061. 